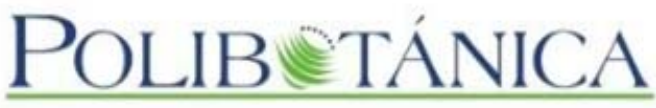

\title{
Polibotánica
}

ISSN electrónico: 2395-9525

polibotanica@gmail.com

Instituto Politécnico Nacional

México

http://www.polibotanica.mx

\section{DISTRIBUCIÓN Y CONDICIONES ECOGEOGRÁFICAS DEL BOSQUE RELICTO DE Abies EN ZONAS MONTAÑOSAS DE TAMAULIPAS.}

\section{DISTRIBUTION AND \\ ECOGEOGRAPHIC CONDITIONS OF RELICT Abies FOREST AT MOUNTAINOUS ZONES OF TAMAULIPAS.}

Requena-Lara, G.N., P.E. Ochoa- Sandoval, J.F. Morales-Pacheco, H.A. Garza-Torres, C. Zamora-Tovar, C.E. González-Romo, A. Guerra-Pérez, J.I. Manzano-Banda y J. TreviñoCarreón.

DISTRIBUCIÓN Y CONDICIONES ECOGEOGRÁFICAS DEL BOSQUE RELICTO DE Abies EN ZONAS MONTAÑOSAS DE TAMAULIPAS.

DISTRIBUTION AND ECOGEOGRAPHIC CONDITIONS OF RELICT Abies FOREST AT MOUNTAINOUS ZONES OF TAMAULIPAS.

\section{POLIBETANICA}

Instituto Politécnico Nacional
Núm. 49: 50-73 México. Enero 2020

DOI: $10.18387 /$ polibotanica.49.4

cC (i) Este es un artículo de acceso abierto bajo la licencia Creative Commons 4.0 Atribución-No Comercial (CC BY-NC 4.0 Internacional). 


\section{DISTRIBUCIÓN Y CONDICIONES ECOGEOGRÁFICAS DEL BOSQUE RELICTO DE Abies EN ZONAS MONTAÑOSAS DE TAMAULIPAS}

\section{DISTRIBUTION AND ECOGEOGRAPHIC CONDITIONS OF RELICT Abies FOREST AT MOUNTAINOUS ZONES OF TAMAULIPAS}

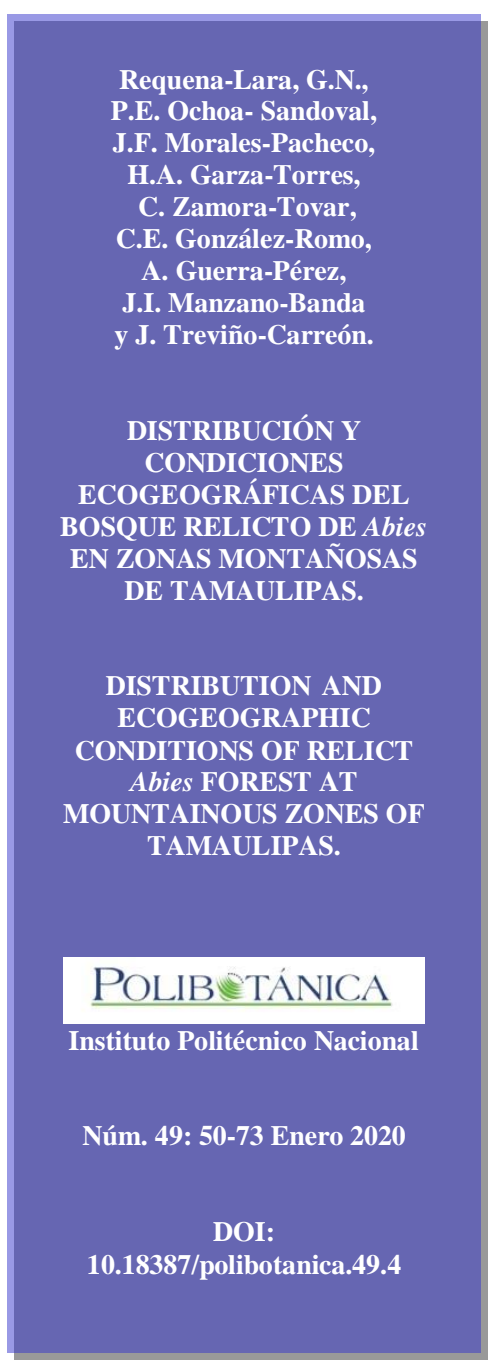

Requena-Lara, G.N.,

Choa- Sandoval,

J.I. Manzano-Banda

y J. Treviño-Carreón.

DISTRIBUCIÓN Y

CONDICIONES

ECOGEOGRÁFICAS DEL

BOSQUE RELICTO DE Abies

DE TAMAULIPAS.

DISTRIBUTION AND

ECOGEOGRAPHIC

CONDITIONS OF RELICT

MOUNTAINOUS ZONES OF TAMAULIPAS.

POLIBETANICA

Núm. 49: 50-73 Enero 2020

10.18387/polibotanica.49.4

\author{
G. N. Requena-Lara \\ Universidad Autónoma de Tamaulipas, Instituto de Ecología Aplicada \\ c/ División del Golfo 356, Col. Libertad, 87019, \\ Ciudad Victoria, Tamaulipas, México. \\ P. E. Ochoa-Sandoval \\ Universidad Autónoma de Tamaulipas, Facultad de Ingeniería y Ciencias. \\ Centro Universitario "Lic. Adolfo López Mateos" \\ Ciudad Victoria, 87149, Tamaulipas, México. \\ J. F. Morales-Pacheco / juanmorales53@ gmail.com \\ H.A. Garza-Torres \\ C. Zamora-Tovar \\ C.E. González-Romo \\ A. Guerra-Pérez \\ J. I. Manzano-Banda \\ Universidad Autónoma de Tamaulipas, Instituto de Ecología Aplicada. \\ c/ División del Golfo 356, Col. Libertad, 87019, \\ Ciudad Victoria, Tamaulipas, México. \\ J. Treviño-Carreón \\ Universidad Autónoma de Tamaulipas, Facultad de Ingeniería y Ciencias. \\ Centro Universitario "Lic. Adolfo López Mateos" \\ Ciudad Victoria, 87149, Tamaulipas, México.
}

RESUMEN: En el noreste de México, el género Abies forma bosques considerados relictos, con distribución sólo reconocida por instancias gubernamentales para el estado de Nuevo León. Dentro del estado de Tamaulipas se conocen cuatro especies de Abies que se encuentran enlistadas por IUCN, pero sólo dos de ellas (A. vejarii y $A$. guatemalensis) forman bosques, siendo las que se encuentran en categorías mexicanas de protección. El uso de herramientas gratuitas de visualización y modelación geoespacial permitió estudiar la distribución relicta de estos bosques tamaulipecos. A través de Puntos de Control en Campo (PCC) se registraron factores ecogeográficos de tres sitios de este bosque, mismos que permitieron establecer características ópticas sobre imágenes de satélite del visualizador Google Earth ${ }^{\mathrm{TM}}$. Con los valores de altitud, pendiente y exposición, se obtuvo un primer modelo (de aproximación), usando álgebra booleana con el módulo Spatial Analyst para ArcView 3.2 de ESRI ${ }^{\mathrm{TM}}$, que se sobrepuso a las imágenes del visualizador, para ajustarlo y obtener un modelo principal. Este modelo sirvió, a su vez, como auxiliar para encontrar la distribución potencial, ya que primero se buscaron registros de Abies en bases de datos, los cuales se sobrepusieron al modelo principal en Google Earth ${ }^{\mathrm{TM}}$, para saber si se encontraban en sitios con características ópticas de bosque similares a los puntos de control; otros puntos fueron agregados sobre el visualizador en lugares donde el INEGI registra la presencia del bosque en Nuevo León. Posteriormente, se obtuvieron los valores para cada una de las variables de WordlClim de los diez puntos obtenidos, estableciendo 
rangos que fueron procesados a través de álgebra booleana; además, se aplicó un análisis de clústers para obtener la similitud bioclimática entre los sitios. La distribución potencial también fue sobrepuesta en Google Earth ${ }^{\mathrm{TM}}$ para repetir el proceso de ajuste del modelo y obtener así la distribución real del bosque de oyamel en Tamaulipas. De esta forma, se obtuvo como resultado una superficie potencial de $165.9 \mathrm{Km}^{2}$, pero la distribución real es de apenas $3.68 \mathrm{Km}^{2}$, lo que representa menos del $1 \%$ del territorio estatal. En los PCCs se presentan condiciones de humedad y temperatura templada todo el año, que son producto de la exposición e inclinación de la ladera; ahí, la humedad depende de la altitud en los sitios de la Sierra Madre Oriental, y de la cercanía al Golfo de México en el bosque de la Sierra de San Carlos; esta diferencia en la provisión de humedad es la variable de disgregación principal entre ambos sitios. Además de estas condiciones, otros factores han permitido la prevalencia de los bosques en Tamaulipas, principalmente a su aislamiento y acceso difícil, por lo que no son aprovechados comercialmente. Algunos lugares de la distribución potencial se encuentran ocupados principalmente por bosques de pino, pero gran parte de la superficie ha sido afectada principalmente por incendios, por lo que presentan chaparrales, matorrales o pastizales inducidos. Por ser un ecosistema aislado y relictual, formado de especies en riesgo y que además no cuenta con protección oficial, puede presentar niveles significativos de fragilidad y vulnerabilidad, especialmente ante las condiciones cambiantes del clima planetario. Conocer su distribución sienta bases para estudios más profundos y estrategias de conservación adecuadas a estos bosques. Finalmente, y a pesar de la limitación de cartografía digital a gran detalle, las herramientas geoespaciales y el método empleado resultaron adecuados para modelar la distribución real del bosque de Abies en el Tamaulipas, siendo más apropiado que el uso de algoritmos de nicho ecológico, debido principalmente a que estos dependen de un elevado número de registros.

Palabras clave: Bosque relictual de Abies, Google Earth ${ }^{\mathrm{TM}}$, Sistemas de Información Geográfica, Tamaulipas, México.

ABSTRACT: In the northeast of Mexico, the genus Abies forms forests considered relicts, with distribution only recognized by governmental instances for the state of Nuevo León. There are four species of Abies known within the state of Tamaulipas, which are listed by IUCN, but only two of them (A. vejarii and A. guatemalensis) form forests, being those found in Mexican protection categories. The use of free visualization tools and geospatial modeling allowed us to study the relict distribution of these Tamaulipan forests. We recorded ecogeographic factors from three sites in this forest, at the Field Control Points (PCC), which allowed to establish optical characteristics on satellite images of the Google Earth TM viewer. With the values of altitude, slope and exposure, we obtained a first model (approximation model), using Boolean algebra with the Spatial Analyst module for ArcView 3.2 of ESRI TM, which was superimposed on the images of the visualizer, to adjust it and obtain a model principal. We added other points on the viewer in places where the INEGI records the presence of the forest in Nuevo León. Subsequently, the values for each of the WordlClim variables of the ten points obtained were extracted, establishing ranges that we processed through Boolean algebra; also, a cluster analysis was applied to obtain the bioclimatic similarity between the sites. The potential distribution was also superimposed on Google Earth TM to repeat the adjustment process of the model and get the real distribution of the Tamaulipan forest. In this way, we obtained a potential area of $165.9 \mathrm{~km}^{2}$, but the actual distribution is only $3.68 \mathrm{~km}^{2}$, which represents less than $1 \%$ of the state territory. In the PCCs there are conditions of humidity and temperate temperature throughout the year, which are the product of the exposure and slope of the hillside; there, humidity depends on the altitude at the sites of the Sierra Madre Oriental, and on the proximity to the Gulf of Mexico in the forest of the Sierra de San Carlos. Which is the main differentiation variable between both sites. In addition to these conditions, other factors have allowed the prevalence of forests in Tamaulipas: they are not harvested commercially, mainly to their isolation and difficult access. Some sites of the potential distribution are occupied primarily by pine forests, but a large part of the surface has been affected mainly by fires, which means that there are chaparrals, shrubs, or induced grasslands. Because it is an isolated and 
relictual ecosystem, formed of species at risk and that also does not have legal protection, it can present significant levels of fragility and vulnerability, especially in the face of changing global climate conditions. Knowing their distribution provides the basis for more in-depth studies and conservation strategies appropriate to these forests. Finally, and despite the limitation of digital cartography in great detail, the geospatial tools and the method used were adequate to model the real distribution of the Abies forest in Tamaulipas, being more appropriate than the use of ecological niche algorithms, mainly due to which they depend on a high number of records.

Key words: Abies relictual forest; Tamaulipas, México; Geographic Information Systems; Google Earth ${ }^{\mathrm{TM}}$.

\section{INTRODUCCIÓN}

En México, los bosques de montaña boreales son relictos del periodo glacial (Pineda, M.; Ortega, M.; Sánchez, R.; Ortiz, G.\& Vázquez, 2013), caracterizados por el género Abies, por lo que se les conoce comúnmente como bosques de Abies, de oyamel o de abeto (Rzedowski, 2006). Leopold, a mitad del siglo pasado, los denominó bosque boreal, debido a sus similitudes florísticas y ecológicas con la Taiga (Rzedowski, 2006). Estos bosques están asociados con especies de otros géneros como Pinus, Pseudotsuga, Picea, Quercus, Arbutus (Ávila, C.; Aguirre, J.; García, 1994; Encina, J.A.; Encina, F.J.; Mata, E.\& Váldez, 2008; Gómez, 2003; IUCN, 2016).

Los bosques de oyamel mexicanos se desarrollan en zonas montañosas con altitudes de 2700 a 3600 m.s.n.m., en sitios templados, con veranos húmedos y caída de nieve invernal (Ávila, C.; Aguirre, J.; García, 1994; Rzedowski, 2006). Se presentan como comunidades aisladas en cañadas, cerros o barrancos profundos, con poca incidencia solar y suelo rico en materia orgánica (Ávila, C.; Aguirre, J.; García, 1994; Hernández, 1985; Pineda, M.; Ortega, M.; Sánchez, R.; Ortiz, G. \& Vázquez, 2013; Rzedowski, 2006); donde las condiciones climáticas son reguladas por oscilaciones diurnas de temperatura y ausencia de inviernos intensos, que mantienen sus actividades fenológicas durante todo el año, a diferencia de las formaciones más norteñas con clima boreal (Rzedowski, 2006).

Tales condiciones regulan su distribución en estados del centro-sur del país (Castellanos-Acuña, Lindig-Cisneros, Silva-Farias, \& Sáenz-Romero, 2014; Manzanilla, 1974) y en zonas norteñas (Domínguez, 1991; Valdez, V.; Foroughbakhch, R; Alanís, 2003), donde son escasos y restringidos (Rzedowski, 2006). No obstante, Domínguez (1991) registra la presencia de estos bosques en la porción tamaulipeca de la Sierra Madre Oriental (SMO), en los cerros El Borrado y Peña Nevada, con dominancia de Abies vejarii Martinez en altitudes de 3500 m.s.n.m.(registrada sólo en los estados de Tamaulipas, Nuevo León y Coahuila, de acuerdo con Gernandt \& Pérez-De La Rosa (2014), así como García (2013) y López (2015) en el cerro del Nacimiento, a 3100 m.s.n.m. También se han reportado en la SMO las especies A. duranguensis var. coahuilensis (I.M. Johnst.) Martinez (Martínez-Méndez, Aguirre-Planter, Eguiarte, \& Jaramillo-Correa, 2016), y A. religiosa (Kunth) Schltdl \& Cham (Earle, 2007), pero formando parte de bosques con dominancia de otras coníferas. Por su parte, en la Sierra de San Carlos, se presentan bosques monoespecíficos de A. guatemalensis Redh., en altitudes de 1000 m.s.n.m. en el Cerro del Diente (Briones Villarreal, 1991; Cavazos, 2000; García, 2013; Valdez, V.; Foroughbakhch, R; Alanís, 2003).

Las cuatro especies registradas para Tamaulipas se encuentran enlistadas por la (IUCN, 2016) bajo diferentes categorías. Pero en México dos de ellas se encuentran bajo protección, de acuerdo a la (SEMARNAT, 2010): A. vejarii Martínez, que es catalogada como amenazada y endémica para México, y A. guatemalensis Redh., en peligro de extinción. Resaltando que estas dos especies son las dominantes de los bosques de Abies del estado. 
La falta de estudios geográficos que determinen la distribución relicta de estos bosques en Tamaulipas y otros aspectos ecológicos, está dada por su difícil acceso territorial debido a la orografía y altitud; además, sus superficies son menores a las cinco hectáreas que representan el área mínima cartografiable de la escala 1:250000, en que se encuentran los mapas de uso de suelo y vegetación oficiales (INEGI, 2013). Sin embargo, su análisis a escalas más detalladas se posibilita con el uso de Sistemas de Información Geográfica (SIG) e información satelital, y herramientas de modelación territorial, un SIG permite conocer la distribución espacial y temporal del área de estudio (Chuvieco, 2011). Por lo tanto, la generación de un modelo ecológico explícitamente espacial (Zavala, M.A.; Díaz-Sierra, R.; Purves, D.; Zea, G.E.; Urbieta, 2006), y sustentado en el análisis de variables ambientales, facilita el estudio y comprensión de los ecosistemas, a través de mapas de distribución a mayor detalle y sus bases de datos asociadas (Lambin, 1994).

Este tipo de modelos han sido de gran utilidad para México, particularmente en zonas con orografía compleja e inaccesible, donde es difícil obtener información de campo (Gámez, 2011); pero aún con su distribución restringida e insular, es necesario generar información de diversa índole sobre estos bosques la implementación de estrategias para su cuidado (GuerreroHernández, Muñiz-Castro, Vázquez-García, \& Ruiz-Corral, 2019). Para generar modelos de distribución, es posible utilizar el módulo Spatial Analyst de ESRITM, diseñado para resolver problemas espaciales o geoestadísticos (Harlow, M.; Jones, C.; Tucker, 2006), lo que permite determinar la presencia de una especie o población, a través del análisis multicriterio (ESRI, 2006), utilizando un mapa por cada variable analizada. Sin embargo, la precisión del modelo depende de la calidad de la información suministrada (Chuvieco, 2011; ESRI, 2006).

Otra tecnología usada para determinar la distribución de comunidades vegetales es la percepción remota (o teledetección), que ha sido usada desde el siglo pasado con imágenes satelitales de alta resolución, pero, de acuerdo con algunos autores (Villers, L.; García del Valle, L.; López, 1998), no es suficiente para el estudio de áreas muy pequeñas, como las que ocupa el bosque de oyamel de carácter relictual. En ese tiempo no era posible diferenciar a detalle asociaciones vegetales de coníferas, pero en la actualidad se ha logrado observarlas con el apoyo de algunos procesos automatizados, como la clasificación orientada a objetos, aplicada a imágenes multiespectrales de muy alta resolución (Peralta-Carreta, Solórzano, FernándezMontes De Oca, \& Gallardo-Cruz, 2016), ya sea en plataformas satelitales o de vehículos aéreos no tripulados. Por otra parte, las imágenes de plataformas satelitales se encuentran disponibles en internet, lo que permite observar a mayor detalle áreas muy pequeñas, diferenciando varias asociaciones vegetales. Por ejemplo, el visualizador de Google Earth ${ }^{\mathrm{TM}}$, que se ha utilizado cada vez con mayor frecuencia (Luvezute, R.M.; Viali, L.; Alexandre, 2014), y en particular para complementar la primera aproximación al estudio de una comunidad vegetal de distribución restringida (Arranz, A.; López,C.; Salinas, C.; Zuñiga, M.; Montorio,R.; Pueyo, 2013; Peralta-Carreta et al., 2016).

Lo anterior justifica la realización de este trabajo, al ser de utilidad en la observación y evaluación de ecosistemas de reducida superficie, considerados relictos. Con ello se genera la posibilidad de establecer un plan de manejo de estos ecosistemas templados y sus especies, dada su vulnerabilidad ante el cambio climático, en que un aumento en la temperatura y diferente régimen pluvial (Guerrero-Hernández et al., 2019), ya no les permitiría desarrollarse a mayores latitudes o altitudes dentro del estado. Hipotéticamente, se plantea si el uso de este método geoestadístico, utilizando las herramientas y datos gratuitos de SIG y teledetección, permite identificar la distribución espacial de ecosistemas de poca cobertura espacial, con lo que se plantea las siguientes interrogantes: ¿Dónde se encuentran los bosques de Abies en Tamaulipas? ¿Es posible localizarlas con herramientas de SIG y visualizadores de imágenes satelitales gratuitos? En consecuencia, se realizó la siguiente investigación, con el objetivo de generar modelos territoriales adecuados que permitan el estudio del bosque de Abies y su distribución en Tamaulipas. 


\section{MATERIAL y MÉTODOS}

El área de estudio se localiza en zonas de alta montaña de la porción tamaulipeca de la SMO (con elevación de 2500 m.s.n.m. o más), ubicadas principalmente en el municipio de Miquihuana. Además, considera la discontinuidad fisiográfica conocida como Sierra de San Carlos, la cual, sin ser de alta montaña, conserva relictos del bosque de Abies en una altitud de 1000 m.s.n.m. (fig. 1).

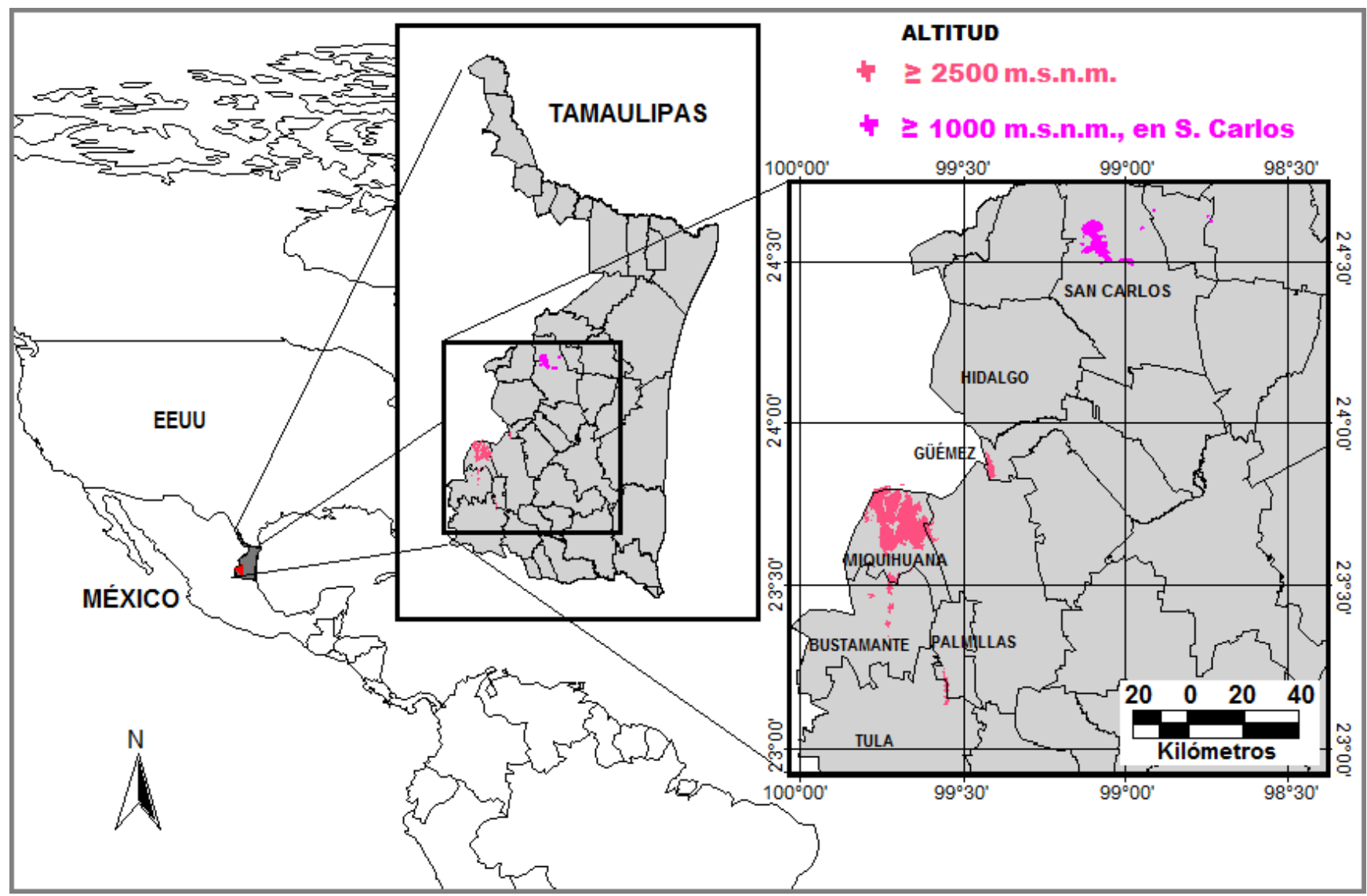

Fig. 1. Ubicación del área de estudio: Municipios de Miquihuana, San Carlos y otros con elevación igual o mayor a 2500 m.s.n.m.

En la primera fase de este trabajo, se seleccionaron dos Puntos de Control en Campo (PCC 1 "Cerro del Nacimiento" y PCC 2 "Sendero del Arroyo sin Nombre") en Miquihuana. En la segunda fase, se estableció el PCC 3 "Cerro del Diente" en la Sierra de San Carlos. Los PCC se utilizaron en el proceso de análisis de imágenes satelitales, y para el registro de los factores ecogeográficos del bosque.

Se midieron los siguientes factores: la altitud (m.s.n.m.) y la temperatura ambiental (con hora de registro) con una estación meteorológica portátil Kestrel 4000, así como la pendiente aproximada (en grados). Además, debido al alcance de este estudio, se anotaron sólo de forma cualitativa datos como las especies arbóreas y arbustivas, la dirección de la pendiente (exposición de la ladera), la presencia de musgos y líquenes, así como de forma relativa tanto el color (negro o café/claro-oscuro) como la humedad del suelo (húmedo/seco). 
Adicionalmente, se entrevistaron habitantes locales de Miquihuana con más de 30 años de residencia en los ejidos circunvecinos (El Aserradero y Valle Hermoso), así como de San Carlos; esto con el propósito de conocer acerca de eventos históricos de heladas, nevadas e incendios, de los que no existen registros oficiales anteriores a la década de los 70. En todos los PCC's se realizaron fotografías escénicas, con el propósito de compararlas con las imágenes del visualizador Google Earth ${ }^{\mathrm{TM}}$ 7.1.2.2041. En este visualizador, se localizaron los PCC's para observar las características ópticas del bosque, especialmente las de rugosidad ("forma cónica" de los individuos, que da una característica visual típica de este bosque en la imagen), de sombras y de densidad de individuos (fig. 2).

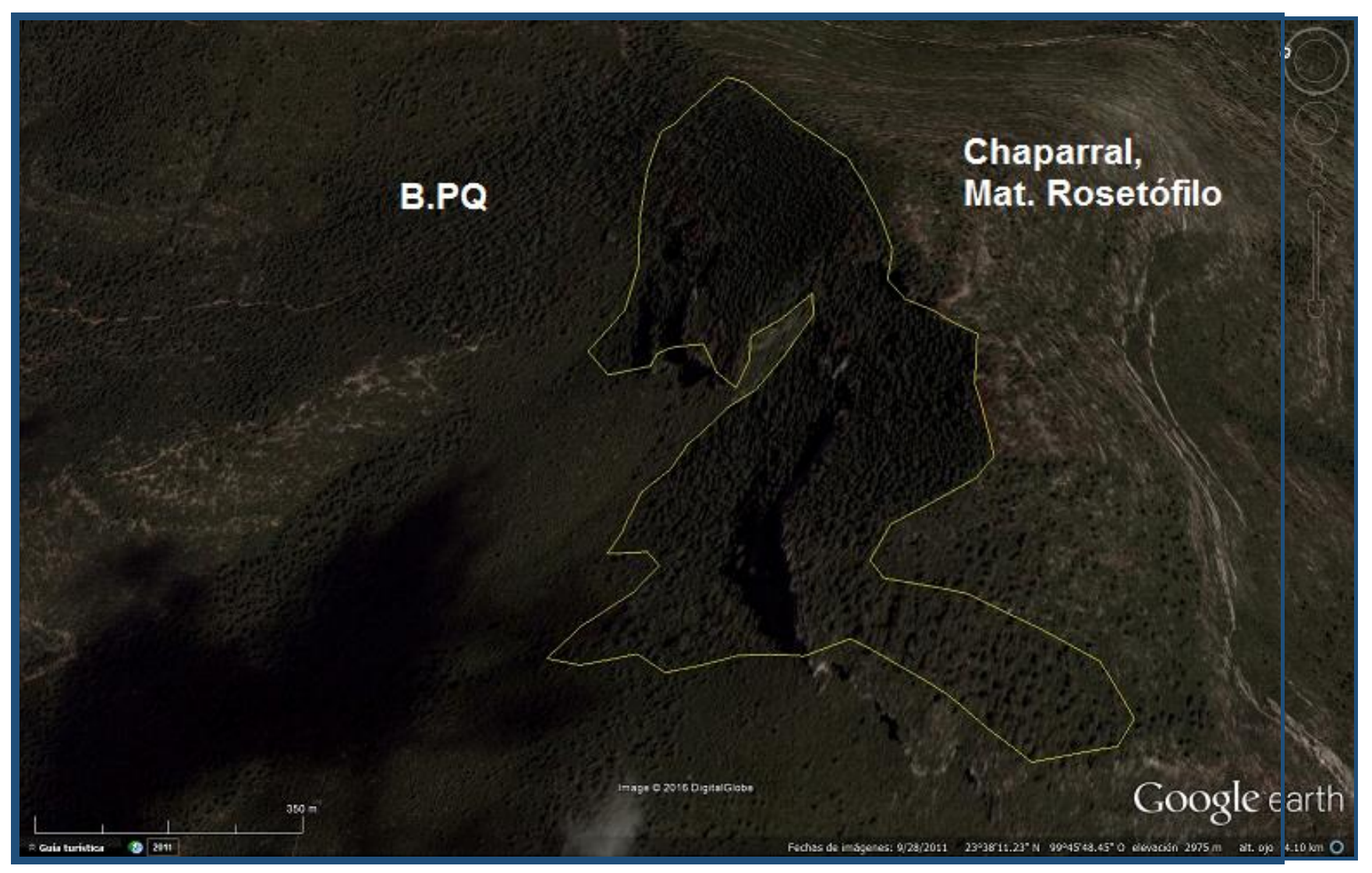

Fig. 2. Imagen de Google Earth ${ }^{\mathrm{TM}}$ del Cerro del Nacimiento (municipio de Miquihuana), donde se delimitó el bosque de Abies visitado (en amarillo). Se observa la diferencia de rugosidad de este bosque con las otras coberturas vegetales $(\mathrm{B} . \mathrm{PQ}=$ bosque mixto de pino-encino; Mat.= matorral). Nota: la orientación del visualizador se muestra al noroeste, con el objeto de destacar el relieve de la imagen.

Una vez registrados los factores ecogeográficos en los PCC's, se seleccionaron la altitud, la pendiente y la exposición para obtener un modelo de "primera aproximación". Mediante el módulo Spatial Analyst para ArcView 3.2 de ESRITM, se utilizó álgebra booleana para producir modelos preliminares para la alta montaña: usando como variables los sitios con 2500 y 3000 m.s.n.m. y pendientes mayores a 20 y $30 \%$, empleando en todos los casos una exposición de ladera Noreste- Noroeste. Se decidió adaptar y modificar para Miquihuana el modelo de mayor restricción (con 3000 m.s.n.m. y 30\% de pendiente); mientras que, para la Sierra de San Carlos se utilizaron los mismos criterios de pendiente y exposición, pero con un rango de altitud de 1000 a 2500 m.s.n.m. 
El modelo de primera aproximación se sobrepuso en Google Earth ${ }^{\mathrm{TM}}$ para adaptarlo manualmente a los sitios donde se observó una textura y rugosidad de imagen similar a los PCC's y así obtener el "Modelo Principal" (M-Ppl). Sobre estas imágenes, se buscaron coincidencias de los polígonos del M-Ppl con sitios que presentaran características ópticas similares a las de los PCC's, en donde se encontraron además algunos polígonos falsos negativos y falsos positivos. Además, se obtuvo apoyo visual de algunas fotografías de usuarios de la plataforma de Panoramio ${ }^{\circledR}$, propiedad de Google ${ }^{\mathrm{TM}}$ y que se encuentran en Google Earth $^{\mathrm{TM}}$, de algunos lugares donde el modelo predijo la distribución de Abies.

Para obtener el "modelo de distribución potencial" (M-Dp) del bosque de Abies, en primer lugar, se consultaron en bases de datos (GBIF, INECOL) sitios de registro en el estado de este género, los cuales se visualizaron en Google Earth ${ }^{\mathrm{TM}}$ para corroborar su presencia dentro de un bosque en el área de estudio, descartando los encontrados dentro de otras asociaciones vegetales. Dado que no había suficientes sitios en Tamaulipas con estas características, se utilizaron registros en el vecino estado de Nuevo León, de preferencia situados en bosques mapeados por INEGI. Se obtuvieron 10 puntos de presencia del bosque (fig. 3), a partir de los cuales se recabaron los valores de las variables bioclimáticas de WorldClim (Hijmans, Cameron, Parra, Jones, \& Jarvis, 2005), para establecer rangos de cada una de ellas (tabla 1).

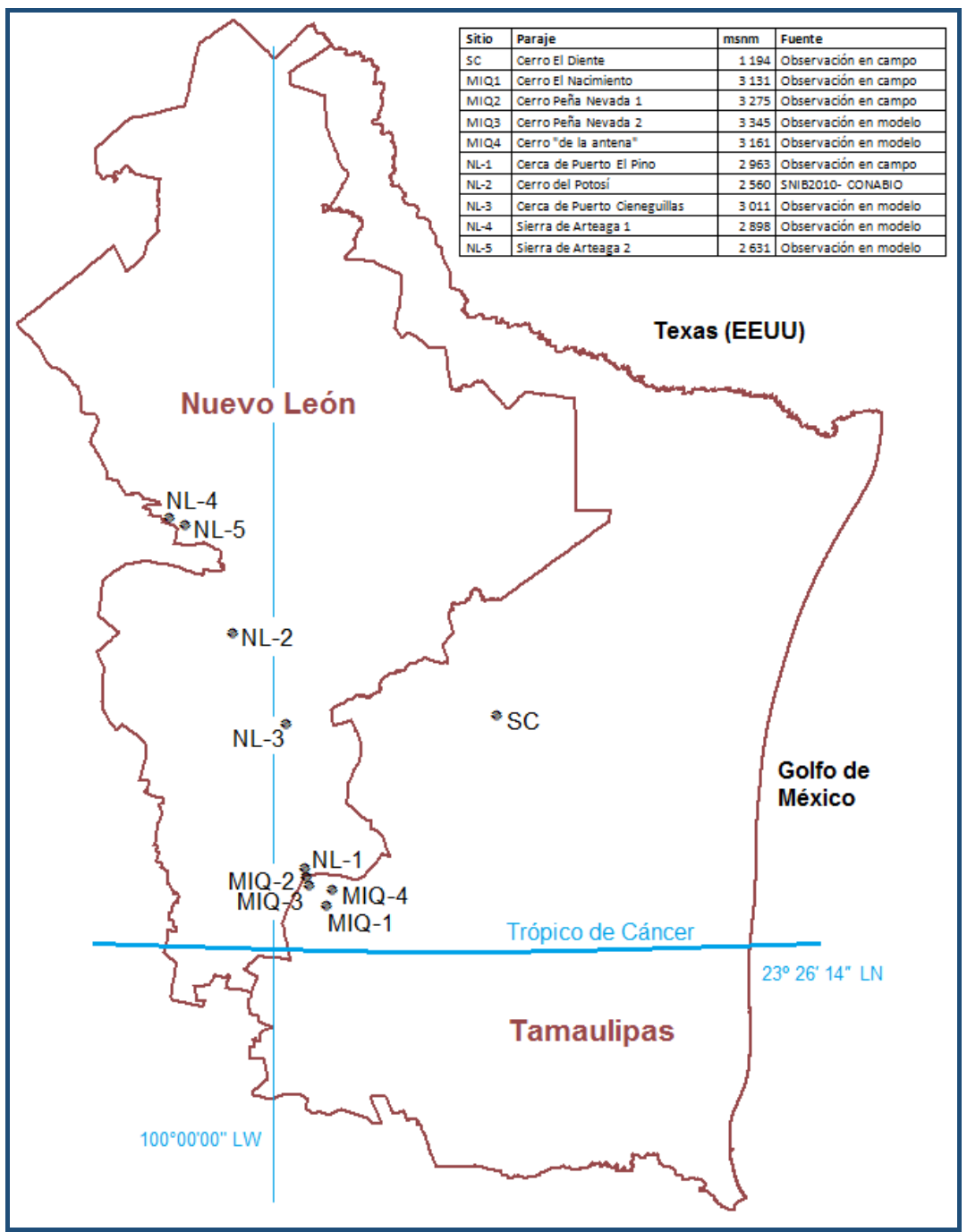

Fig. 3. Sitios con presencia de bosque de Abies, usados para establecer los rangos de las variables bioclimáticas. 
Tabla 1. Variables de WorldClim (Hijmans et al., 2005) y sus valores (Temperatura en ${ }^{\circ} \mathrm{C}$ y precipitación en mm) tomados de sitios con presencia de bosque de Abies $(\mathrm{SC}=\mathrm{San}$ Carlos; $\mathrm{MIQ}=$ Miquihuana; $\mathrm{NL}=$ Nuevo León). Los rangos utilizados se muestran en las columnas Min/Máx.

\begin{tabular}{|c|c|c|c|c|c|c|c|c|c|c|c|c|}
\hline \multirow[b]{2}{*}{ Variable } & \multicolumn{10}{|c|}{ Valores de las variables en cada sitio } & \multirow[b]{2}{*}{ Min } & \multirow[b]{2}{*}{ Máx } \\
\hline & SC & MIQ1 & MIQ2 & MIQ3 & MIQ4 & NL-1 & NL-2 & NL-3 & NL-4 & NL-5 & & \\
\hline $\begin{array}{l}\text { BIO1 Temperatura media } \\
\text { anual }\end{array}$ & 19.1 & 11.7 & 11.0 & 11.4 & 10.1 & 11.5 & 13.0 & 10.5 & 11.1 & 11.1 & 10.1 & 19.1 \\
\hline $\begin{array}{l}\text { BIO2 Rango de temperatura } \\
\text { diurno medio (Temp. } \\
\text { Máxima - Temp. Mínima) }\end{array}$ & 13.6 & 14.2 & 14.2 & 14.3 & 13.8 & 14.4 & 14.5 & 14.0 & 13.4 & 13.3 & 13.3 & 14.5 \\
\hline $\begin{array}{l}\text { BIO3- Isotermalidad (Bio2 / } \\
\text { Bio7) }(* 100) .\end{array}$ & 5.5 & 6.6 & 6.7 & 6.7 & 6.7 & 6.7 & 6.7 & 6.7 & 6.3 & 6.3 & 5.5 & 6.7 \\
\hline $\begin{array}{l}\text { BIO4- Estacionalidad de } \\
\text { temperatura (desviación } \\
\text { estándar * 100) }\end{array}$ & 36.82 & 21.32 & 20.54 & 20.90 & 19.64 & 20.79 & 21.99 & 19.87 & 24.86 & 23.92 & 19.64 & 36.82 \\
\hline $\begin{array}{l}\text { BIO5- Temperatura máxima } \\
\text { del mes más caliente }\end{array}$ & 30.3 & 22.4 & 21.6 & 22.1 & 20.5 & 22.2 & 23.5 & 20.8 & 21.5 & 21.4 & 20.5 & 30.3 \\
\hline $\begin{array}{l}\text { BIO6- Temperatura mínima } \\
\text { del mes más frío }\end{array}$ & 5.8 & 1.1 & 0.5 & 0.8 & 0 & 0.8 & 1.9 & 0.1 & 0.3 & 0.5 & 0 & 5.8 \\
\hline $\begin{array}{l}\text { BIO7- Rango de temperatura } \\
\text { anual (Bio5-Bio6) }\end{array}$ & 24.5 & 21.3 & 21.1 & 21.3 & 20.5 & 21.4 & 21.6 & 20.7 & 21.2 & 20.9 & 20.5 & 24.5 \\
\hline $\begin{array}{l}\text { BIO8- Temperatura media } \\
\text { del trimestre más húmedo }\end{array}$ & 21.5 & 13.2 & 12.4 & 12.8 & 11.4 & 12.9 & 14.8 & 11.9 & 13.3 & 13.1 & 11.4 & 21.5 \\
\hline $\begin{array}{l}\text { BIO9- Temperatura media } \\
\text { del trimestre más seco }\end{array}$ & 14.8 & 9.3 & 10.4 & 10.7 & 9.5 & 10.8 & 10.3 & 9.6 & 8.0 & 8.1 & 8 & 14.8 \\
\hline $\begin{array}{l}\text { BIO10- Temperatura media } \\
\text { del trimestre más caliente }\end{array}$ & 23.2 & 14.1 & 13.3 & 13.7 & 12.3 & 13.8 & 15.4 & 12.7 & 13.8 & 13.7 & 12.3 & 23.2 \\
\hline $\begin{array}{l}\text { BIO11- Temperatura media } \\
\text { del trimestre más frío }\end{array}$ & 13.9 & 8.6 & 8.0 & 8.3 & 7.3 & 8.4 & 9.8 & 7.6 & 7.5 & 7.7 & 7.3 & 13.9 \\
\hline $\begin{array}{l}\text { BIO12- Precipitación total } \\
\text { anual }\end{array}$ & 919 & 789 & 777 & 765 & 862 & 753 & 623 & 789 & 613 & 623 & 613 & 919 \\
\hline $\begin{array}{l}\text { BIO13- Precipitación del } \\
\text { mes más húmedo }\end{array}$ & 215 & 150 & 144 & 143 & 164 & 140 & 104 & 145 & 101 & 104 & 101 & 215 \\
\hline $\begin{array}{l}\text { BIO14- Precipitación del } \\
\text { mes más seco }\end{array}$ & 22 & 19 & 20 & 20 & 22 & 20 & 22 & 24 & 18 & 19 & 18 & 24 \\
\hline $\begin{array}{l}\text { BIO15- Estacionalidad de la } \\
\text { precipitación (coeficiente de } \\
\text { variación) }\end{array}$ & 75 & 64 & 62 & 62 & 63 & 62 & 54 & 59 & 56 & 57 & 54 & 75 \\
\hline $\begin{array}{l}\text { BIO16- Precipitación del } \\
\text { trimestre más húmedo }\end{array}$ & 425 & 347 & 338 & 334 & 382 & 327 & 263 & 341 & 277 & 281 & 263 & 425 \\
\hline $\begin{array}{l}\text { BIO17- Precipitación del } \\
\text { trimestre más seco }\end{array}$ & 79 & 76 & 76 & 75 & 83 & 74 & 73 & 84 & 66 & 67 & 66 & 84 \\
\hline $\begin{array}{l}\text { BIO18- Precipitación del } \\
\text { trimestre más caliente }\end{array}$ & 331 & 297 & 288 & 286 & 318 & 280 & 218 & 279 & 217 & 220 & 217 & 331 \\
\hline $\begin{array}{l}\text { BIO19- Precipitación del } \\
\text { trimestre más frío }\end{array}$ & 80 & 80 & 83 & 81 & 90 & 80 & 77 & 89 & 71 & 71 & 71 & 90 \\
\hline
\end{tabular}

Las variables y los rangos se ingresaron al módulo de ArcView 3.2 Spatial Analyst, sub módulo MapQuery, para obtener el "modelo de distribución potencial" (M-Dp) del bosque, a partir de álgebra booleana. Este proceso consiste en que, por medio de una ecuación booleana, se ordena al modelador que encuentre primero los pixeles de una variable mapeada que pertenezcan al rango encontrado, por ejemplo: (Biol $\geq 10.1$ and Biol $\leq 19.19$ ); y luego se solicita que coincidan con el rango de una segunda variable, una tercera y así sucesivamente; por ejemplo: $[[(\mathrm{Bio} 1 \geq 10.1$ and $\mathrm{Bio} 1 \leq 19.19)]$ and $[(\mathrm{Bio} 2 \geq 10.3$ and $\mathrm{Bio} 2 \leq 14.5)]$ and... $[(\mathrm{Bio} 19 \geq 71$ and 


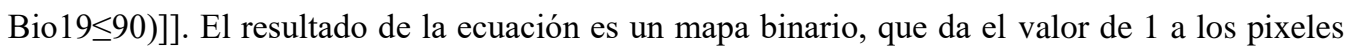
donde el resultado de la ecuación es verdadero y 0 donde no lo es.

La modelación por álgebra booleana generó un archivo ráster (GRID de ESRI), cuyos pixeles con valor de 1 (resultado verdadero) fueron vectorizados (generación de archivo .SHP) y se exportados a un archivo tipo .KML del visualizador Google Earth ${ }^{\mathrm{TM}}$. Como última parte del proceso de mapeo, el M-Dp (en KML) se utilizó para ajustar manualmente el M-Ppl sobre dicho visualizador, modificando o digitalizando los sitios con características ópticas de bosque de Abies, dentro y en las inmediaciones del M-Dp, para obtener el "modelo de distribución real" (M-Dr) en Tamaulipas.

Finalmente, se comprobó el grado de similitud entre los sitios, para lo que se realizó un análisis de clústers jerárquicos, mediante el software SPSS (IBM, 2015), usando el número de variables (Med1 a Med19, las mediciones de WorldClim) y sus valores para cada sitio (denominados L1 a L10). Se aplicó un método de agrupación de variables siguiendo el vecino más cercano y usando la medida de correlación de Pearson, es decir, el grado de covariación entre las distintas variables relacionadas linealmente. Como de antemano se conocía que el sitio L1 (San Carlos), cuya altitud diferente a los demás podría influir en las pruebas, se realizaron dos procesos por separado, para obtener dos dendrogramas: Caso 1, donde incluyó todos los sitios; y Caso 2, sin el sitio L1.

\section{Resultados}

\section{Características de los sitios visitados (PPC)}

Las condiciones ecogeográficas del bosque de Abies, registradas a 3120 m.s.n.m. en el Cerro del Nacimiento (PCC 1), visitado en enero de 2015 (invierno), a las 12:22 horas fueron: la temperatura ambiental de $12{ }^{\circ} \mathrm{C}$, la humedad relativa de $77.1 \%$, la pendiente cercana a $70^{\circ}$ con exposición de $20^{\circ} \mathrm{NW}$. El suelo presentaba alto contenido de hojarasca y un color oscuro, con abundante musgo, líquenes escasos y algunas herbáceas, pero no se observó manejo ni aprovechamiento forestal relevante, sólo algunos renuevos cortados, así como algunos tocones en descomposición. En este sitio se identificaron las siguientes especies arbóreas: A. vejarii, Pseudotsuga sp. y Arbutus xalapensis, con densidades aproximadas de 80.8\%, 14.7\%, y 4.3\%, respectivamente. En el estrato arbustivo se observaron Heimia sp.; Quercus sp., Bourvardia ternifolia; Abies sp.; Arctostaphylos pungens.; Arbutus xalapensis; Ageratina sp. y Cercocarpus sp.

Respecto al sitio PCC 2, ubicado a 2652 m.s.n.m. en el sendero del arroyo "sin nombre", se observaron individuos de Abies formando parte de un bosque mixto con encino y pino, en enero de 2015 (invierno). Se presentó una temperatura ambiente de $15.2^{\circ} \mathrm{C}$, a las 14:28 horas, una humedad relativa de $62 \%$, estando ubicado sobre una pendiente de aproximadamente $60^{\circ}$ y exposición $5^{\circ} \mathrm{NE}$. En este sitio, el suelo presentó un color negro oscuro, totalmente cubierto de hojarasca. El musgo resultó escaso y existente sólo en algunos troncos en descomposición o en algunas bases de los árboles de mayor tamaño. Los líquenes fueron abundantes, mientras que el sotobosque fue de baja densidad y no se observó evidencia de un manejo forestal o pecuario reciente. En el estrato arbóreo dominaron varias especies de Quercus, seguido de Pinus spp, Pseudotsuga sp y Cornus disciflora; en el estrato arbustivo se observó la presencia de Litsea glaucescens y Arbutus xalapensis.

En cuanto a las condiciones ecogeográficas del Cerro del Diente (PCC 3), en las inmediaciones del lugar se encontraron individuos de A. guatemalensis, diseminados en un ecosistema con características de un bosque mesófilo, a 900 m.s.n.m.; sin embargo, la formación del bosque de Abies se observó a una altitud entre 1000 y 1200 m.s.n.m., en compañía de algunos Pinus y Quercus, tanto adultos como juveniles y renuevos. En ese sitio, las condiciones fueron: altitud de 1102 m.s.n.m., pendiente de $45^{\circ}$ con exposición aproximada de $30^{\circ} \mathrm{NW}$, una temperatura ambiental de $17.2{ }^{\circ} \mathrm{C}$ y una humedad de $72.1 \%$ (16:42 horas, abril de 2016), así como el suelo 
totalmente cubierto por líquenes y musgos, hojarasca abundante. En la parte baja (de 850 a 1000 m.s.n.m.), se observaron ocasionalmente renuevos y juveniles de Abies entre el bosque mesófilo, acompañado por los géneros Carya, Pinus, Quercus, con sotobosque abundante, una temperatura ambiental de $20.1^{\circ} \mathrm{C}$ y una humedad de $83.4 \%$ registradas a las $14: 47$ horas.

\section{El modelo de distribución potencial}

El M-Dp (fig. 4) generó un total de once polígonos dentro del territorio de Tamaulipas, con superficies que varían de 76.8 a 10,289 hectáreas, y cuya sumatoria resulta en 16,585 ha. Esto representa el territorio tamaulipeco donde se presentan las características bioclimáticas propias para el establecimiento de este bosque. Incluye sitios con altitudes mayores a 2400 m.s.n.m. en la SMO, y 850 m.s.n.m. en la Sierra de San Carlos, y se presenta casi totalmente en el territorio del municipio de Miquihuana, con un solo polígono en San Carlos y otro en el municipio de Palmillas.

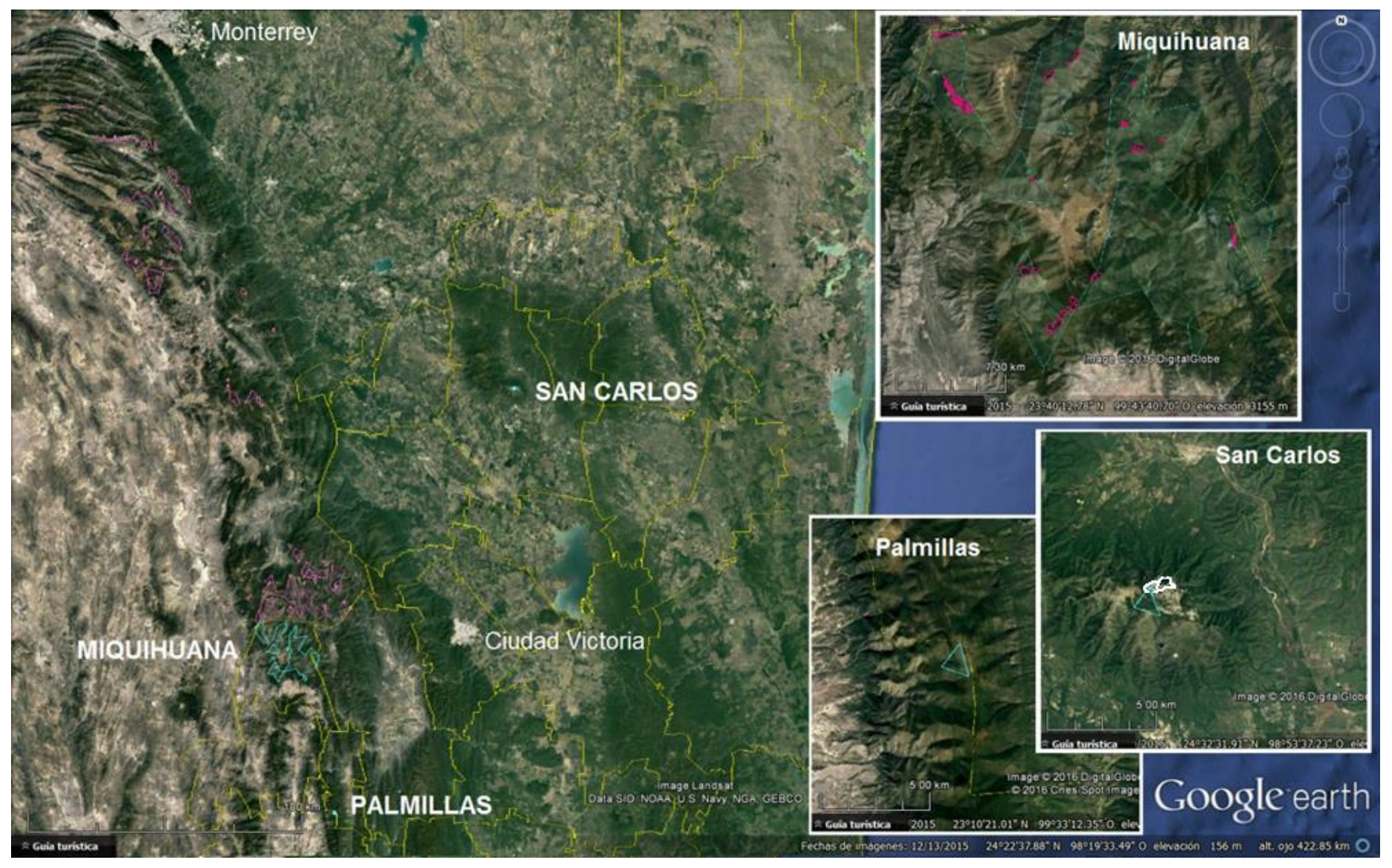

Fig. 4. Distribución potencial del bosque de oyamel en Nuevo León (polígonos rosas) y Tamaulipas (polígonos azules). En el inserto se observan los detalles del modelo en Tamaulipas: los polígonos rojos en Miquihuana y blancos en San Carlos indican la distribución real del bosque (a mayor detalle en las figuras 7 y 8).

A través del M-Dp, fue posible determinar que las condiciones bioclimáticas para el establecimiento del bosque de Abies se presentan en una superficie 45 veces mayor a la distribución observada en imágenes de satélite, por lo que contiene polígonos identificados durante su ajuste con las imágenes de satélite de Google Earth ${ }^{\mathrm{TM}}$ como falsos positivos o negativos. Esto es especialmente notorio en el municipio de Miquihuana, donde la distribución potencial incluye amplias superficies dominadas por matorrales o sitios sin vegetación aparente, 
mientras que en una proporción visiblemente menor se encuentran algunos bosques de pino o de pino-encino. Otra parte importante del modelo es que incluye sitios con pendientes que reciben la mayor radiación solar, contrarias a las norte-oeste donde se observó la formación del bosque de Abies.

Los polígonos con respuestas falsas positivas, incluyen características que el modelo arrojó como propicios para el desarrollo del bosque de Abies, pero en la imagen se presentaban matorrales y vegetación secundaria (fig. 5). Por otra parte, en los sitios "falsos negativos" se encontraron evidencias del bosque que el modelo no alcanzó a predecir (fig. 6).

\section{El modelo de distribución real}

El M-Dr (fig. 7) incluye 40 sitios con bosque de Abies en Tamaulipas, que suman una superficie total de 328.1 ha en el municipio de Miquihuana y 40 en el de San Carlos (fig. 8), ya que no se encontraron superficies de textura óptica similar en el polígono de Palmillas. En total, este ecosistema representa el $0.8 \%$ de la superficie de mayor elevación en el Estado, y de esta superficie, el $68.8 \%$ lo forman diez polígonos con 16 a 42.72 hectáreas, mientras que otros ocho son polígonos de cinco a diez hectáreas, que ocupan el $14.3 \%$ de este bosque.

\section{El análisis de similitud}

El análisis de Clústers estableció para el Caso 1 (fig. 9) dos grupos principales entre los sitos analizados: aquellos localizados en la Sierra Madre Oriental (L2 a L-10), y como se había previsto, el de la Sierra de San Carlos (L1). Además, en el primero se observaron dos subgrupos, el primero perteneciente a tres de los sitios de Nuevo León (L7, L9 y L10) y el segundo a los de Tamaulipas (excepto el L6 y L8). Esto da la impresión de un agrupamiento en los sitios de la SMO con respecto a su latitud (grupos del norte o del sur, dentro del área de estudio).

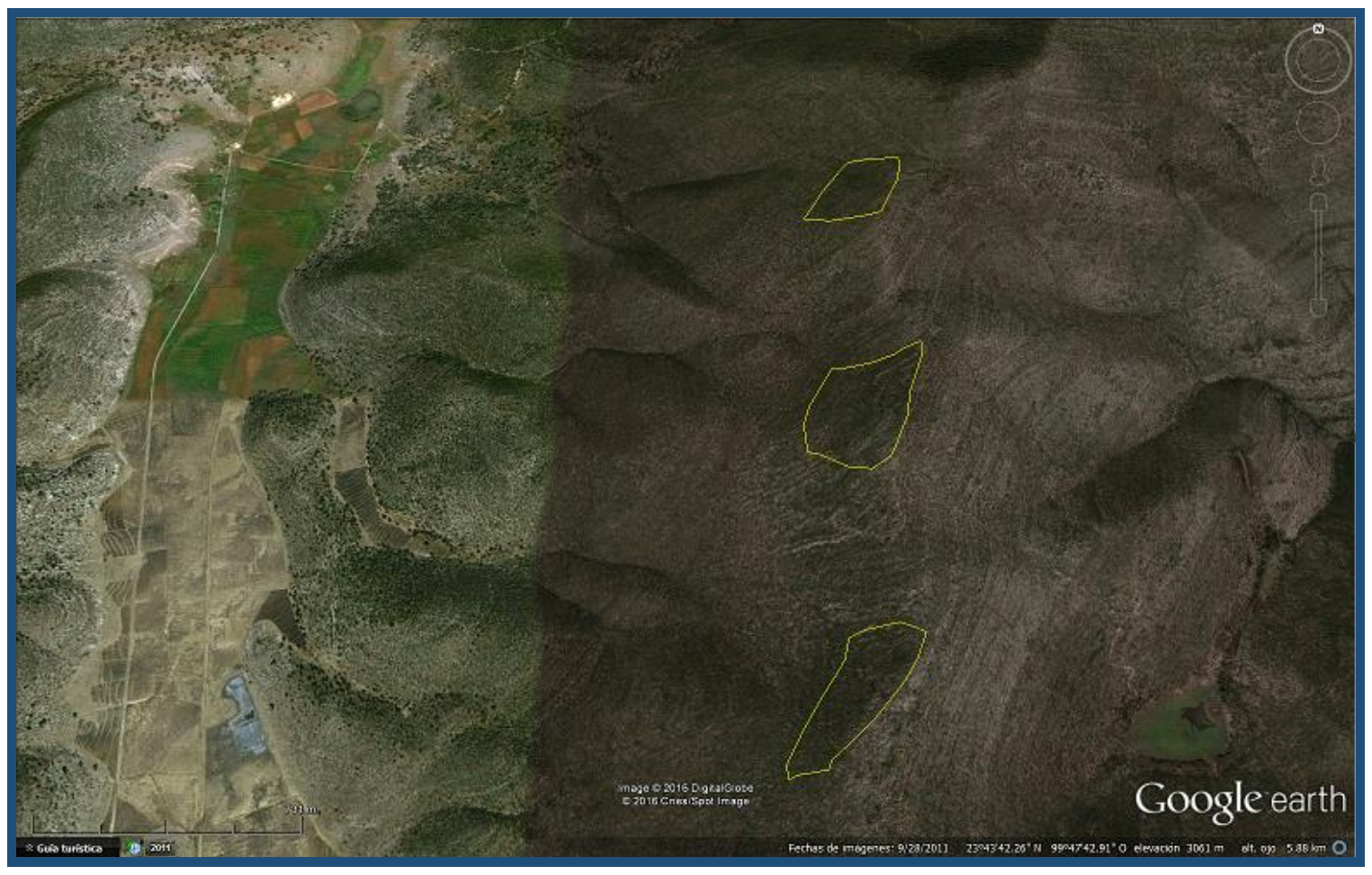

Fig. 5. Sitio con el modelo arrojando falsos positivos (polígonos con perímetro amarillo): no existe bosque de Abies. 


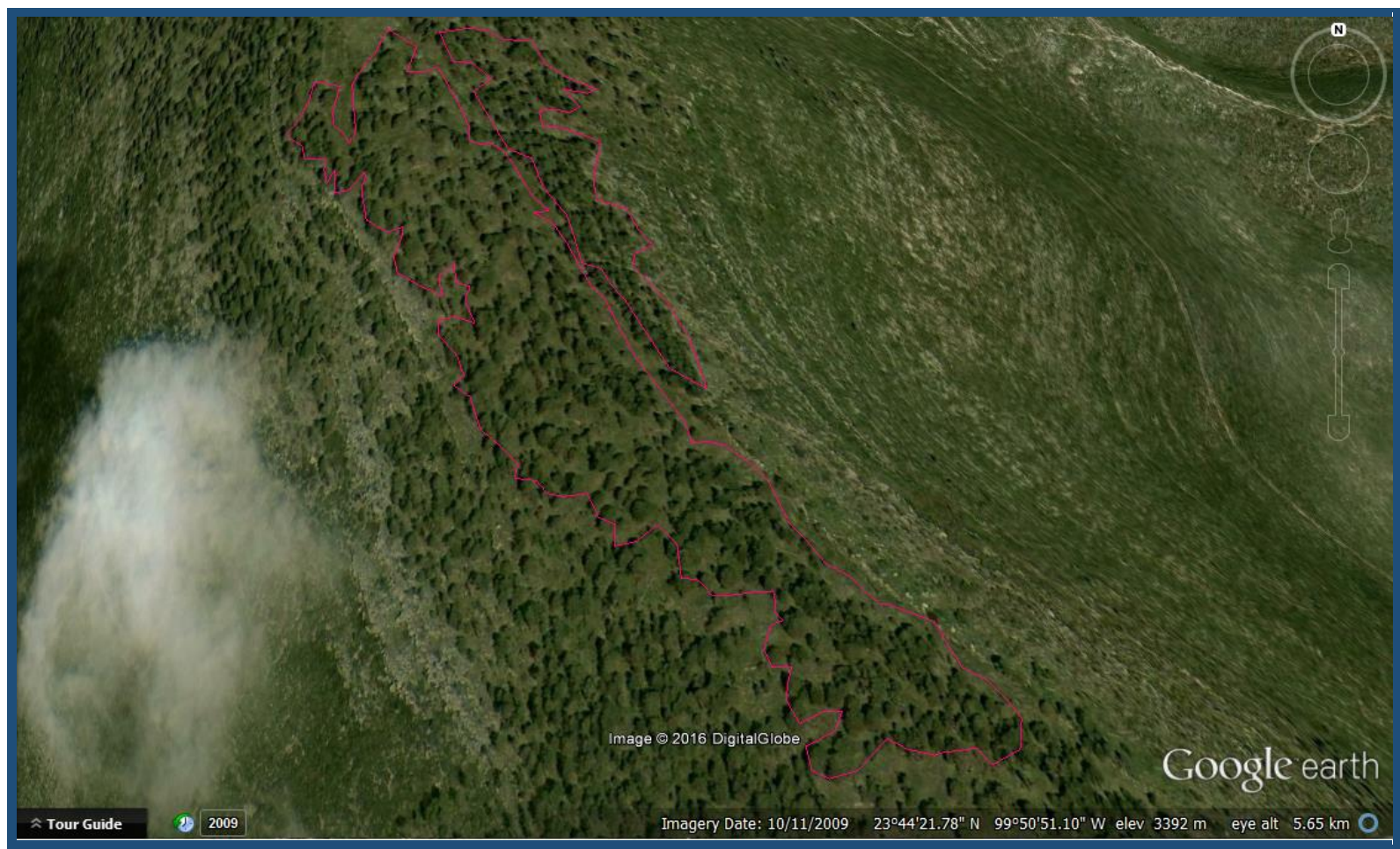

Fig. 6. Sitio con el modelo arrojando falsos negativos (polígonos con perímetro magenta): existe bosque de Abies.

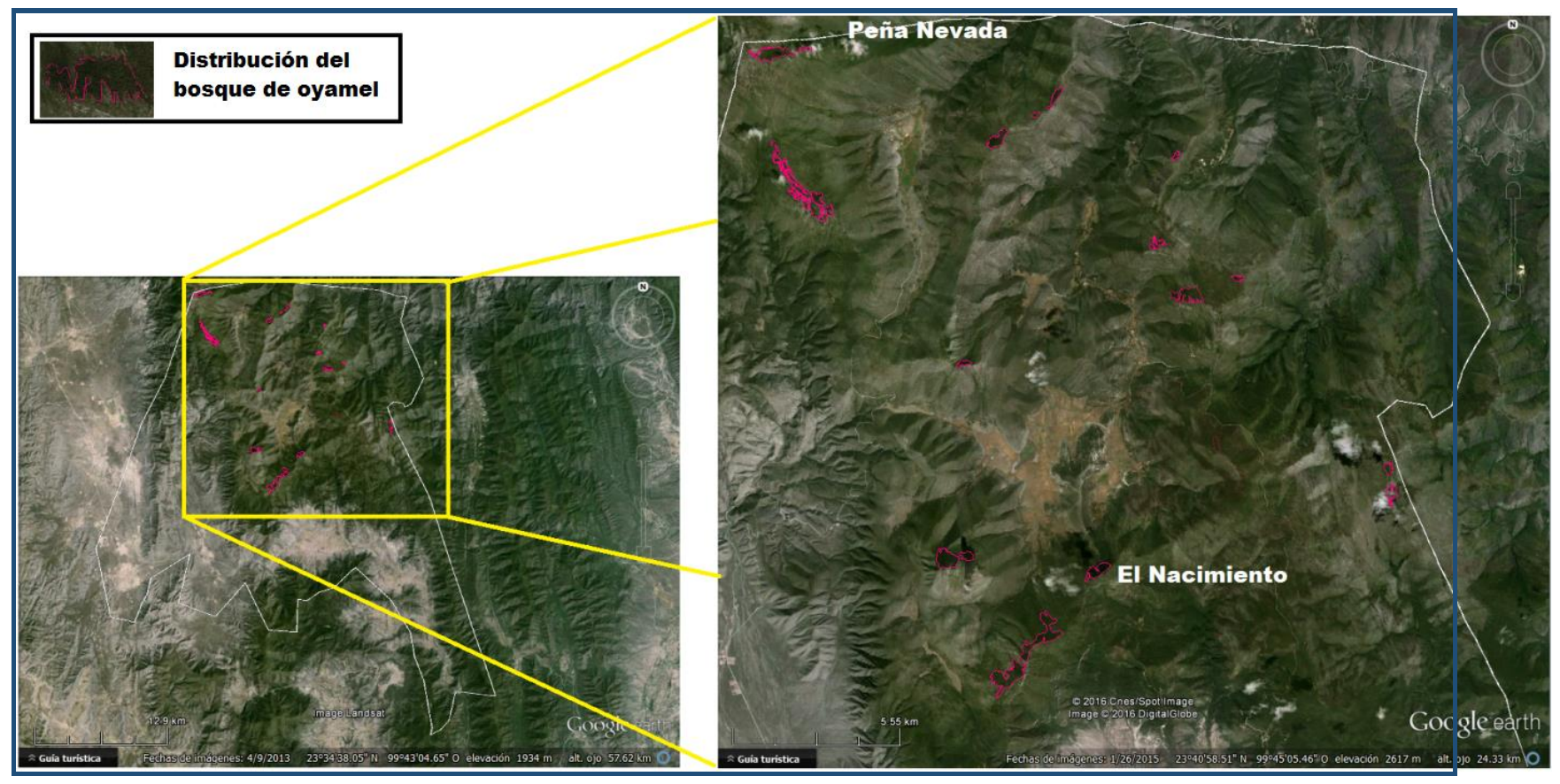

Fig. 7. Distribución del bosque de oyamel en el municipio de Miquihuana, Tamaulipas. 


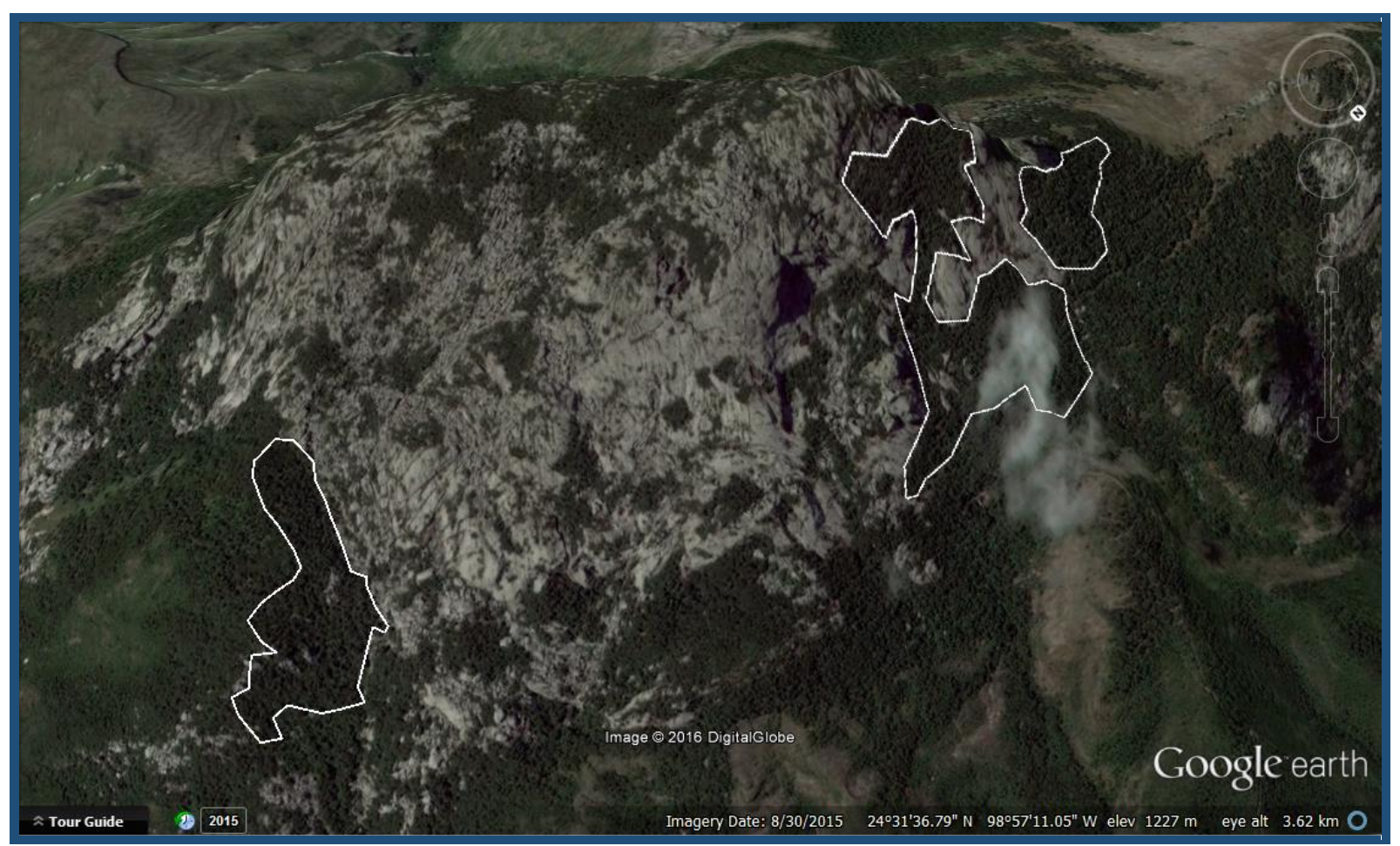

Fig. 8. Relictos de bosque de Abies guatemalensis, observados en el Cerro del Diente, municipio de San Carlos (polígonos con perímetro blanco). Nota: la orientación del visualizador se muestra al sureste, con el objeto de destacar el relieve de la imagen.

Sin embargo, el dendrograma del Caso 2 (fig. 10) remarca la diferenciación entre los subgrupos de la SMO, ya que en este se nota que, a pesar de la cercanía latitudinal del sitio de Cerro del Potosí (L7) con el Puerto Cieneguillas (L8), este último muestra mayor afinidad con los sitios más sureños.

\section{DISCUSIONES}

En Tamaulipas se ha reportado la presencia de individuos de Abies formando parte de bosques templados. Entre ellos, (López, 2015) los reporta en un sitio en Miquihuana con un estrato arbóreo dominado por Quercus, con una frecuencia de un individuo adulto de Abies sp. por cada diez árboles adultos observados, lo que puede deberse a que germinaron en condiciones adecuadas de umbría y humedad; sin embargo, no formaron una comunidad boscosa probablemente debido a la competencia interespecífica con latifoliadas y otras coníferas, que no se presenta cuando abundan individuos de Abies. Esta escasez de congéneres estaría privando a las plántulas del "resguardo" con que cuentan al establecerse bajo adultos de su misma especie, de acuerdo con lo que señala Williams (2009).

También se encontraron individuos de Abies sp. en otros sitios de la SMO en Tamaulipas, especialmente en los municipios de Gómez Farías al sureste de Miquihuana y de Hidalgo, al norteste (García, 2013). En sitios de esos municipios, se observaron condiciones de retención de humedad similares a las que se presentan en Miquihuana y San Carlos: pendientes orientadas al norte-noreste, pero con menor inclinación y en altitudes de 1800 a 2000 m.s.n.m. Sin embargo, en ninguno de esos lugares se observaron individuos formando poblaciones, sino como parte de 
bosques mixtos de otras coníferas y latifoliadas. De acuerdo con Martínez-Méndez et al. (2016), la especie con idoneidad adecuada de nicho en las condiciones del municipio de Hidalgo es A. duranguensis var. coahuilensis, de la que se observaron en campo varios individuos y grupos pequeños de juveniles. Farjon (2013) indica que existe un registro en ese municipio de A. vejarii en el Herbario de Nueva York, pero necesita verificarse, mientras que (Domínguez, 1991) lo registró en "Arroyo Oscuro" (en ese mismo municipio). A. religiosa fue observada sólo en el municipio de Gómez Farías, pero ni en este municipio, ni el de Hidalgo se encontraron características ópticas de formación boscosa sobre el visualizador Google Earth ${ }^{\mathrm{TM}}$.

En cuanto a las condiciones del sustrato en los bosques de Abies visitados, las características de los suelos observados coinciden con las reportadas por Nieto (1995) quien encontró en el centro del país condiciones similares en bosques de oyamel, con suelos de alto contenido de materia orgánica. Por su parte, Farjon (2013) refiere que los suelos donde se desarrolla la especie $A$. vejarii son húmedos, pero con bajo contenido de humus. En los cerros El Nacimiento y El Diente, se observó una alta densidad de musgo, lo que podría estar influyendo en la retención de la humedad en el suelo y en la protección de las raíces ante las heladas y nevadas; a diferencia de los suelos observados en Hidalgo, con predominancia de hojarasca y musgo presente casi siempre sólo sobre troncos muertos.

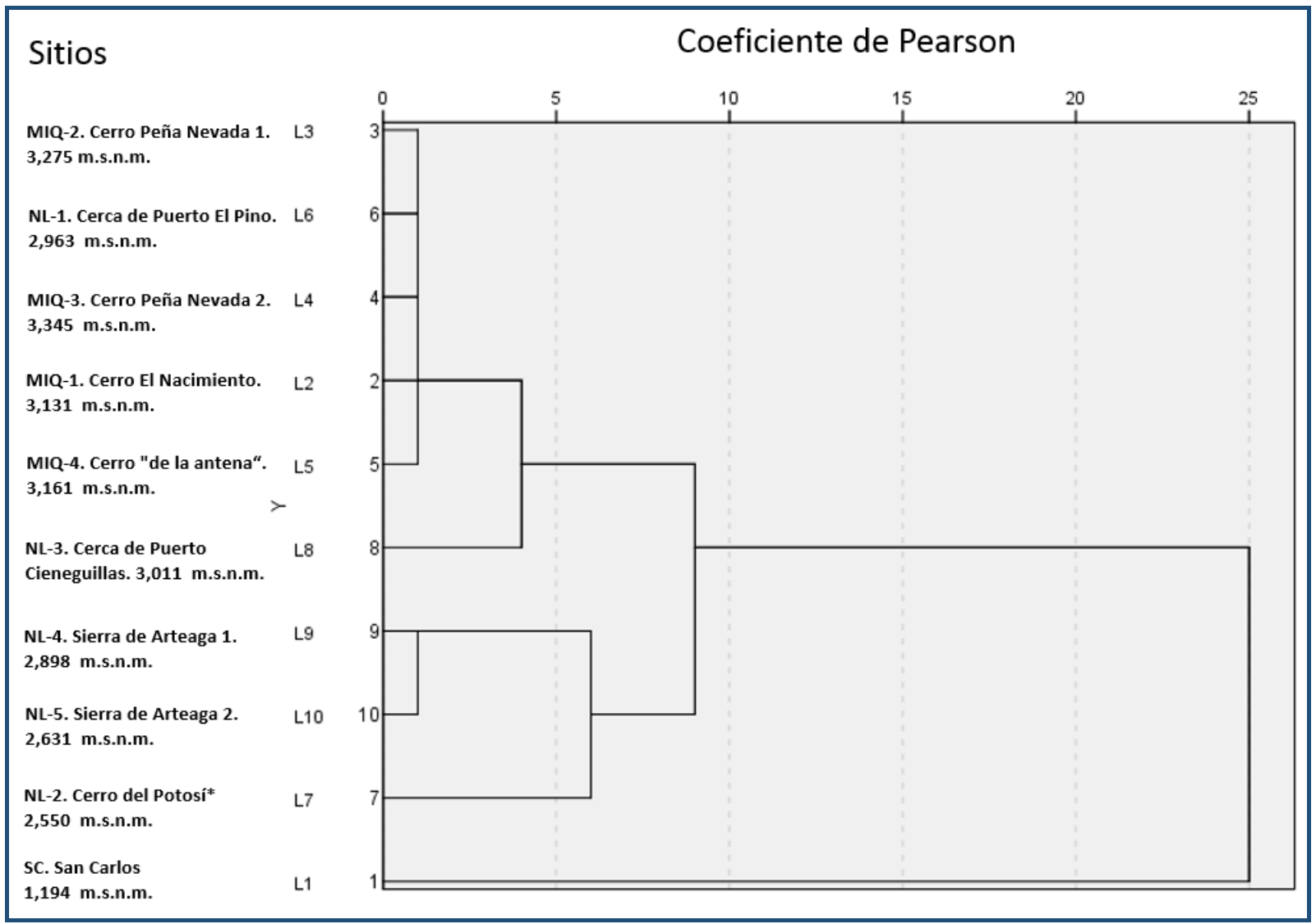

Fig. 9. Dendrograma que utiliza un enlace promedio entre el agrupamiento de los sitios estudiados, destacando como un primer grupo los sitios de la SMO y de forma separada el sitio de San Carlos. 


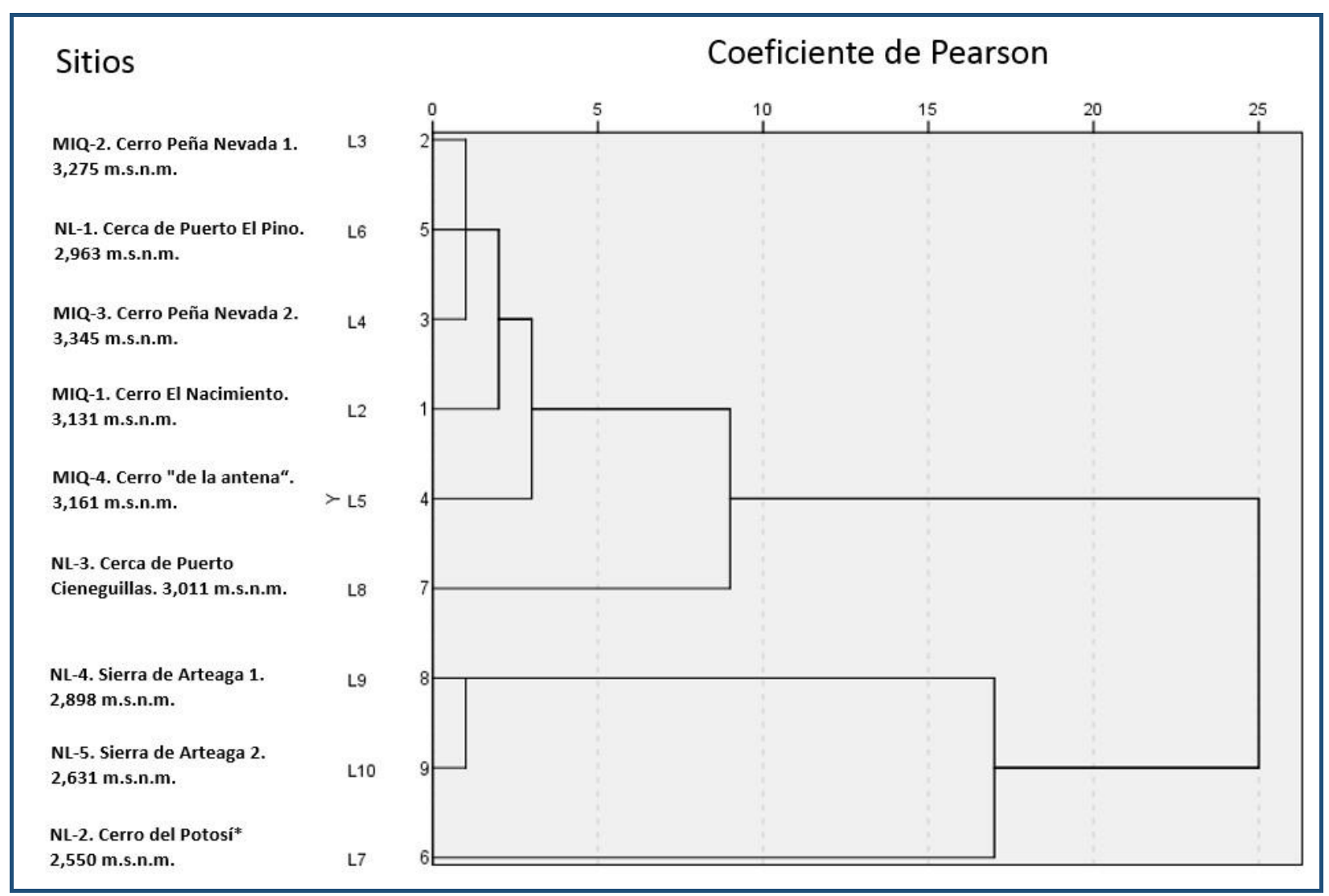

Fig. 10. Dendrograma que utiliza un enlace promedio entre el agrupamiento de los sitios de la SMO estudiados. En este caso, destacan como grupos principales los de mayor altitud, y en el segundo los más norteños.

Referente a las especies asociadas al género Abies, en el municipio de Miquihuana existe similitud con lo reportado por Domínguez (1991) en un bosque de dicho género en Veracruz, donde el estrato arbóreo no registró Pseudotsuga sp., pero incluye a los géneros Pinus, Quercus y Cupressus; además, en el estrato arbustivo coincide con los géneros Quercus y Arbutus. Por su parte, Farjon (2013) coincide con lo anterior, al señalar que las especies comúnmente asociadas con la especie A. vejarii Martínez son de los géneros Pinus, Pseudotsuga y Quercus. En contraste, en San Carlos, se observaron diferentes encinos y nogales de especies indeterminadas, que se hicieron más abundantes que Abies al disminuir la altitud a menos de 1000 m.s.n.m.

En la mayoría de las zonas montañosas de Tamaulipas se carece de estaciones meteorológicas, por ello se consideró que la información recabada en campo, aunque es de suma utilidad para el análisis de los modelos de distribución, sólo puede utilizarse con carácter orientativo. No obstante, las mediciones de temperatura y humedad estacional coinciden con reportes de otros sitios donde se presenta el bosque de Abies (Castellanos-Acuña et al., 2014; Cavazos, 2000; Hernández, 1985; Nieto, 1995; Pineda, M.; Ortega, M.; Sánchez, R.; Ortiz, G.\& Vázquez, 2013; Rzedowski, 2006). Además, en el campo se observó una similitud con las variables termales de WorldClim (Hijmans et al., 2005), ya que no se presentó lluvia en las fechas de visita: la temperatura media del trimestre más frío (enero-marzo) en Miquihuana $\left(8.6^{\circ} \mathrm{C}\right.$ en WordlClim y $12.2^{\circ} \mathrm{C}$ en campo) y en San Carlos, la media del trimestre más seco (febrero-abril), de 14.8 en WorldClim (Hijmans et al., 2005) y $17.2^{\circ}$ en campo. 
De acuerdo con las personas entrevistadas, en las montañas de Miquihuana no todos los años se presentan condiciones de alta pluviosidad o caída de nieve invernal (esta última sólo esporádicamente, durante enero o febrero), que han sido indicadas para estos bosques por otros autores (Castellanos-Acuña et al., 2014; Hernández, 1985; Nieto, 1995; Pineda, M.; Ortega, M.; Sánchez, R.; Ortiz, G.\& Vázquez, 2013; Rzedowski, 2006). Esta diferencia entre las condiciones observadas por pobladores locales y las informadas por los autores mencionados indican la posibilidad de que el bosque relicto de Abies, aún sin nevadas invernales o precipitación recurrentes, subsiste en Tamaulipas debido las temperaturas templadas y al mantenimiento de humedad por la presencia importante de nubes, coincidiendo con Guerrero et al. (2019), y que se presentan en altitudes mayores a 3000 m.s.n.m.

En San Carlos, un grado de latitud más al norte que Miquihuana y dos mil m.s.n.m. más bajo, el relicto de bosque de Abies depende además de otros factores que conservan la humedad (Valdez, V.; Foroughbakhch, R; Alanís, 2003) a pesar de las temperaturas de verano y la prácticamente nula presencia de nevadas (Gobierno del Estado de Tamaulipas, 2011), que los habitantes de San Carlos indican sólo haberlas observado aproximadamente cada diez años entre 1958 y 1980, cada cinco entre hasta 1995 y de ahí hasta el año 2016. Ahí se conserva por la provisión de vientos frescos y húmedos del Golfo de México, que se encuentra aproximadamente a $130 \mathrm{Km}$ al este del mencionado relicto. Sus condiciones de umbría, humedad y temperatura se mantienen por la exposición e inclinación de la ladera en que se asienta, lo que coincide con Guerrero-Hernández et al. (2019), quienes encontraron que la humedad proporcionada por niebla en periodos de sequía y una baja evapotranspiración ayudan al bosque de oyamel a mantener la humedad alta.

Por tanto, es posible inferir que, más que la altitud de la montaña, la exposición de ladera al Noroeste y Norte es un factor determinante para la presencia del bosque de Abies en Tamaulipas, puesto que sobre la SMO se ubica en altitudes superiores a los 2500 m.s.n.m. y en San Carlos sobre los 1000 m.s.n.m., generalmente sobre cañadas con pendientes mayores a 20\% orientadas hacia el noreste, norte o noroeste. Guerrero-Hernández et al. (2019) coinciden con esto, ya que encontraron que la distribución del bosque de oyamel en Jalisco depende de diferencias de altitud, precipitación anual e invernal y precipitación horizontal (niebla) en los meses más fríos y secos, aún antes que condiciones de pedregosidad o edáficas. Además, en modelaciones de otros bosques con Abies como dominante o monoespecífico Gutiérrez, O., Cámara, R., \& García (2016) coindicen en cuanto a que encontraron como factores determinantes la humedad elevada, temperaturas "frescas" (media de $2.7^{\circ} \mathrm{C}$ en el mes más frío, contra $\operatorname{los} 2.9^{\circ} \mathrm{C}$ de este trabajo) y predominancia de exposición norte. El valor de la pendiente coincide con la observada por otros autores en bosques de oyamel del estado de Coahuila Encina, J.A.; Encina, F.J.; Mata, E.\& Váldez (2008), donde se encuentra en laderas de 30 a $70 \%$ de inclinación; además, de acuerdo con Ávila, C.; Aguirre, J.; García (1994) en exposiciones al norte y noroeste existe alta influencia de vientos húmedos, lo que favorece condiciones de umbría y humedad en estas latitudes del territorio mexicano.

Al revisar los valores bioclimáticos de WordlClim (Hijmans et al., 2005) por medio del análisis de similitud, se observó una agrupación inicial que discriminó el sitio de la Sierra de San Carlos, de los ubicados en la SMO. A este respecto, se debe señalar que el modelo de distribución potencial construido con dichas variables, discriminó sitios donde se registraron individuos de Abies sin formar bosques. Esto puede explicarse porque, si bien las variables termales en el municipio de Hidalgo son similares a las registradas para la Sierra de San Carlos (ambos sitios con valores en general más altos que otros de la SMO), existen dos importantes condiciones que marcan la diferencia: primero, el rango de temperara diurna en Hidalgo es mayor $\left(14.8^{\circ} \mathrm{C}\right)$ que el del modelo $\left(13.3\right.$ a $\left.14.5^{\circ} \mathrm{C}\right)$, lo que estaría indicando una mayor potencialidad de evapotranspiración o de insolación, equivalente a una cuarta parte del rango, y que podría diferenciar estos sitios de las condiciones de umbría señaladas por Williams (2009) y por Guerrero-Hernández et al. (2019) para la formación del bosque; y segundo, la precipitación en el trimestre más seco y frío (enero-marzo) es menor para Hidalgo y la Sierra de 
San Carlos que para la SMO, por lo que disminuyen las posibilidades de que la humedad se mantenga por la ocurrencia de heladas o nevadas características de la alta montaña de la SMO. Sin embargo, en la Sierra de San Carlos la humedad es proporcionada por la entrada de vientos frescos y húmedos provenientes del vecino Golfo de México, $130 \mathrm{Km}$ al oriente; esto coincide con los sitios estudiados en Jalisco por Guerrero-Hernández et al. (2019), que, aunque se encuentran en latitudes más tropicales y de menor altitud que en la SMO, se ubican entre 70 y $80 \mathrm{Km}$ del Océano Pacífico.

Es importante mencionar que las condiciones encontradas in situ en el Cerro de El Diente en San Carlos, coinciden con las mencionadas por Briones Villarreal (1991), excepto que, tanto las altitudes registradas en campo, como las ubicadas sobre el visualizador Google Earth ${ }^{\mathrm{TM}}$, difieren de las documentadas por el autor (de 1300 a 1400 m.s.n.m.). Sin embargo, esas condiciones concuerdan con Cavazos-Camacho (2000), que observó el bosque de Abies entre 1000 y 1200 m.s.n.m. y con Martínez-Méndez et al. (2016), quienes señalan que algunos sitos con altitudes menores a 1000 m.s.n.m. pueden albergar un entorno adecuado para este género. Además, las señales ópticas (textura, rugosidad o sombras) de este bosque en el visualizador no pudieron ser observadas en otras partes más altas de la Sierra (situadas entre 10 y 18 kilómetros al noroeste del Cerro del Diente).

En cuanto al segundo grupo de localidades establecido por el análisis de similitud, se ubican sobre la SMO en altitudes mayores a 2500 m.s.n.m., con baja temperatura, umbría y alta humedad propios para el desarrollo del bosque. Sin embargo, aunque en otros lugares de la SMO se presentan condiciones similares que permiten la presencia de individuos de Abies, la formación del bosque sólo se observa en los sitios predichos por el M-Dp. Esto podría tener explicación en lo referido por Williams (2009), quien señala que, como las semillas de Abies son dispersadas por el viento, el establecimiento de las plántulas se favorece cuando germinan resguardadas en zonas de media sombra, casi siempre bajo individuos de su misma especie. Además, la competencia interespecífica con otras coníferas y latifoliadas es otro elemento observado, que posiblemente esté limitando la formación de este bosque en el Estado.

Otro factor trascendental para la existencia de bosques de Abies en Tamaulipas es que, a pesar de que SEMARNAT (2007) reporta su amplio uso como recurso maderable en el país, en el Estado no se manejan ni aprovechan sus especies, en parte debido a su difícil accesibilidad. Esto coincide con Valdez, V.; Foroughbakhch, R; Alanís (2003), quienes mencionan que en Nuevo León el hecho de contar con una ubicación alejada "de la presencia humana" favorece la prevalencia de bosques de Abies y Cupressus. Y aunque los habitantes en Miquihuana señalaron que, en ocasiones, han usado ramas o juveniles de abeto como ornamento navideño (al igual que en San Carlos, de acuerdo con Cavazos (2000)), pero por su escasez y la dificultad en llegar a esos sitios, generalmente suelen usar pinos como alternativa. Esto confirma lo indicado por Farjon (2013), acerca de que la importancia del abeto como fuente de madera es baja, debido a que son árboles relativamente raros y con una distribución limitada.

Al definir la distribución del bosque en el área de estudio, es necesario señalar que los relictos encontrados no aparecen en el mapa de vegetación y uso de suelo de (INEGI, 2013), ya que la superficie es menor al área mínima cartografiable (5 hectáreas) de la escala 1:250000 que utiliza. Incluso con tecnología satelital de alta resolución (de mayor detalle que los mapas de INEGI), algunos autores como Villers, L.; García del Valle, L.; López (1998) encontraron problemas para separar asociaciones de coníferas entre sí, especialmente las establecidas en cañadas y laderas con fuertes pendientes, como en las que se encuentra el bosque relicto de Abies en Tamaulipas. Por ello, dichos autores sugieren el uso de imágenes de alta resolución sólo para "grandes grupos vegetales" (refiriéndose a su extensión territorial), debido a que las diferencias espectrales entre asociaciones de coníferas "no es perceptible".

De acuerdo con la cartografía digital de INEGI (2013) más de la mitad de la superficie de los relictos del bosque de oyamel en Miquihuana se encuentra en terrenos clasificados como 
bosques mixtos (de pino-encino o encino-pino) con vegetación secundaria. Otra parte de los relictos se clasifican como coníferas, mientras que dos de ellos entran como bosque mixto primario (tabla 2); cabe señalar que, en el municipio de San Carlos, la clasificación de los relictos es similar (bosque de encino-pino y bosque de pino). Esto coincide con Gutiérrez, O., Cámara, R., \& García (2016), ya que la distribución de organismos oficiales para bosques monoespecíficos o con dominancia de Abies es más amplia que la real, y también se encuentran individuos mezclados en bosques mixtos de pino y encino.

Tabla 2. Superficie y tipo de bosque en que se clasifican relictos de bosque de Abies en Miquihuana, de acuerdo con la cartografía oficial (INEGI, 2013).

\begin{tabular}{|l|c|c|c|}
\hline \multicolumn{1}{|c|}{ Vegetación } & Núm. relictos & Hectáreas & \% \\
\hline Bosque de Encino-Pino con vegetación secundaria & 43 & 178.65 & 54.4 \\
\hline Bosque de Pino & 12 & 147.71 & 45.0 \\
\hline Bosque de Pino-Encino & 2 & 1.75 & 0.5 \\
\hline
\end{tabular}

La cobertura y distribución de los relictos del bosque en Miquihuana (casi un 70\% de la superficie en diez polígonos mayores a 16 hectáreas, pero 22 polígonos ocupan apenas $14 \%$ del área) sugieren que el ecosistema puede encontrarse significativamente fragmentado, lo que confirma la aseveración de Farjon (2013) de que las poblaciones de la especie A. vejarii (dominante en los relictos de Miquihuana), se encuentran "severamente fragmentadas". Sin embargo, es imprescindible resaltar que, si se suma la superficie total de relictos de bosque de Abies en Miquihuana al área de ocurrencia de la especie A. vejarii Martínez estimada por Farjon (2013), este ecosistema representa el $2.23 \%$ del área total de presencia de la especie en el mundo. A su vez, el porcentaje para la especie A. guatemalensis var. guatemalensis en San Carlos representaría el 0.15\% de la superficie estimada para esa subespecie por Gardner (2013).

Es importante señalar que la diferencia significativa entre el modelo de distribución real de los relictos de bosque de oyamel y el de distribución potencial producido con el análisis multicriterio con variables de WorldClim (Hijmans et al., 2005), se debe principalmente a que el territorio propicio para el desarrollo del bosque (distribución potencial) se encuentra ocupado principalmente por sitios desprovistos de vegetación arbórea; especialmente en el área de Miquihuana. En esos lugares prosperan matorrales rosetófilos, chaparrales y pastizales, que es la vegetación colonizadora producto de los repetidos incendios forestales recurrentes que han afectado esos lugares, y que han sido observados ya en imágenes satelitales LANDSAT de 1973 (Requena, 2013). Los habitantes locales entrevistados confirmaron haber observado diversos incendios en las partes altas de las montañas, que consumieron bosques de encino, pino, pino y encino y "pino y abeto" durante las décadas de los años 50-60 (comunicación personal: señor Ernesto, 2004, ejido La Marcela; Sr. Noé, 2015, ejido El Aserradero; señor J. Verdines y señora Sarita de Verdines, 2015, ejido Valle Hermoso).

Lo anterior puede explicar los polígonos con respuesta positiva falsa producidos por el modelo de distribución potencial, pues lo más probable es que se haya perdido la cobertura vegetal boscosa (no necesariamente de Abies) por perturbación en el ecosistema, debido a que, de acuerdo con lo manifestado por los pobladores locales, y que coincide con el argumento de (Farjon, 2013), son sitios de incendios recurrentes con un aislamiento tal que son eventos muy difíciles de controlar. Esto provocaría el desarrollo posterior de matorrales o chaparrales, así como la inhibición del establecimiento y crecimiento de vegetación arbórea. En el caso contrario, se encontraron falsos negativos principalmente por las siguientes razones: a) el 
bosque se encuentra en la parte baja de cañones con pendiente menor a la modelada, pero que guardan humedad suficiente para su desarrollo; b) sitios mayores a 3000 m.s.n.m., con condiciones suficientes para el desarrollo del bosque, que son independientes de la ladera o de la exposición, donde la sombra es ofrecida por los individuos adultos, al tiempo que mantienen la humedad provista por masas nubosas.

Otros modelos han sido producidos para representar la distribución del género Abies en México, como el caso de Martínez-Méndez et al. (2016), quienes elaboraron el nicho ecológico de varias especies de Abies en el país, con base en registros de bases de datos y usando variables WordlClim (Hijmans et al., 2005) y topográficas con el algoritmo de máxima entropía (MaxEnt). Estos autores encontraron una idoneidad de nicho mayor a 50\% en la Sierra Madre Oriental (incluyendo el municipio de Miquihuana) para A. duranguensis var. coahuilensis y A. vejarii Martínez, coincidiendo con las observaciones en campo y el modelo de distribución real del presente trabajo. Sin embargo, su modelo más norteño del nicho idóneo para $A$. guatemalensis Rehder no alcanza el estado de Tamaulipas, lo que contradice los hallazgos de Briones Villarreal (1991), así como los observados en el presente trabajo para el municipio de San Carlos. A este respecto, Gutiérrez, O., Cámara, R., \& García (2016) coinciden en afirmar que en su modelación de nicho ecológico de Abies pinsapo Boiss ocurrieron "errores de omisión de poblaciones completas".

Lo anterior destaca una limitación al modelar la distribución de especies con el algoritmo de nicho ecológico, en contraste con el modelo basado en álgebra booleana usado en esta investigación: el primero depende fuertemente de los puntos de registro que alimentan el modelo, de los que toman los requisitos de nicho de la especie estudiada (Gutiérrez Hernández, Cámara-Artigas, \& García, 2018); y el segundo de la precisión de la cartografía digital empleada. En el caso de la distribución de nicho ecológico de Martínez-Méndez et al. (2016), el modelador no encontró nicho para A. guatemalensis Rehder en Tamaulipas, debido a que no usaron los registros de Briones Villarreal (1991), además de que descartaron un registro de la Sierra de San Carlos (reportado en el IBUNAM, núm. de catálogo 820456, a una altitud de casi 500 m.s.n.m.) y uno en Coahuila (reportado por el INECOL, núm. de catálogo K422946), por considerarlos como puntos climáticos extremos, donde se presentan valores atípicos climáticos ( sitios en que fue registrada la especie, pero es poco probable conocer si son parte de su distribución natural).

Finalmente, y de acuerdo con Guerrero-Hernández et al. (2019), los relictos de bosque de Abies comprenden una distribución "insular y restringida", como ocurre en Tamaulipas. Su dependencia de factores bioclimáticos muy específicos, como la precipitación invernal, que suelen ser los meses más secos, los expone a una sensible vulnerabilidad ante las fluctuaciones del clima actual y el pronóstico de alta posibilidad de cambio en el régimen a inviernos más secos; coincidiendo con Gutiérrez, O., Cámara, R., \& García (2016) en cuanto a que bosques de oyamel con una distribución tan restringida como el de A. pinsapo en el sur de España se enfrentan a perspectivas de reducción de su superficie debidas al calentamiento global. Esto hace que los bosques de Abies de Tamaulipas sean comunidades de alta fragilidad, por lo que, concordando con los autores citados, deben establecerse planes de manejo y conservación, en los sitios localizados en este estudio.

\section{CONCLUSIONES}

\section{De la distribución del bosque de Abies en Tamaulipas}

Las condiciones ecogeográficas de Tamaulipas que permiten la presencia del género Abies formando bosques se deben a la alta humedad y temperaturas frescas producidas por la combinación de tres factores preponderantes: la exposición norte-noroeste de la ladera, su pronunciado escarpado y una temperatura templada (pero contrastante entre diurna y nocturna) a lo largo del año. Estas condiciones se presentan en los municipios de Miquihuana, en altitudes 
mayores a 2500 m.s.n.m. y con presencia esporádica de nevadas y heladas invernales, así como en San Carlos (entre 950 y 1200 m.s.n.m.), donde su cercanía al Golfo de México mantiene la humedad, y la latitud norteña y su exposición le proporciona la temperatura templada.

En contraste, en el suroeste del Estado existen sitios donde se superan los 2500 m.s.n.m. y las temperaturas son frescas, pero no se observan bosques de Abies debido a la falta de humedad ocasionada por el efecto de sombra orográfica de la SMO. Además, existen entornos de baja altitud y exposición similares al bosque de Abies en San Carlos en sitios de la SMO del noreste de Tamaulipas, donde la limitación parece deberse a una menor humedad invernal. Por su parte, en la región de barlovento de la SMO y en otras regiones montañosas del estado (como la Sierra de Tamaulipas) existe suficiente entrada de humedad del Golfo de México, pero no se presentan bosques de Abies por ausencia de temperaturas lo suficientemente bajas, que es característica de latitudes más tropicales.

El aislamiento geográfico, la escasa accesibilidad y las condiciones de humedad y temperatura baja de los bosques de Abies parecen ser las principales circunstancias para que esta comunidad vegetal se haya mantenido en Tamaulipas. No obstante, si tales condiciones se suman al estatus de riesgo de sus especies, puede inferirse que estos ecosistemas se encuentran sensiblemente frágiles y vulnerables ante situaciones de calentamiento global, de contaminación del aire, incendios forestales, el cambio de uso del suelo, la erosión y la extracción ilegal de recursos naturales. Por ello, conocer su distribución actual, las condiciones ecológicas del hábitat, estructura y dinámica vegetal, así como la historia biogeográfica de estos ecosistemas permitirá proponer medidas adecuadas para su manejo óptimo y su posible conservación.

\section{De la metodología empleada}

Las herramientas de SIG y sensores remotos utilizadas en este trabajo arrojaron resultados confiables que permitieron obtener una distribución potencial del bosque de Abies en Tamaulipas. Sin embargo, el principal limitante de esa modelación es que, debido a la inexistencia de cartografía digital a escala detallada, no fue posible incluir en el análisis otros factores son determinantes para la presencia del bosque de Abies. Entre ellos se encuentran el tipo de suelo, las rocas y la frecuencia y estacionalidad de las precipitaciones. A pesar de ello, se evidencia que procesos con algoritmos de nicho ecológico realizados por otros autores no resultan adecuados para modelar este bosque en el área de estudio, debido a que requieren de un número elevado de registros de las especies, además de que el área mínima cartografiable de los mapas bioclimáticos disponibles para esos procesos es mayor al tamaño de los relictos en la región.

El análisis multicriterio con álgebra booleana resultó especialmente útil para generar los mapas de distribución potencial, que en una primera aproximación integran pocas características de búsqueda, pero que pueden orientar el análisis de la distribución de ecosistemas cuando se cuenta con escasez de sitios de registro, de tal manera que los muestreos en el campo sean más dirigidos. No obstante, no se recomienda usar modelaciones con sólo tres factores para ecosistemas con mayor extensión y una complejidad superior de requerimientos de búsqueda. Así mismo, y para futuros estudios de distribución potencial y real, se deberá incluir otros factores ecogeográficos a mayor detalle, imágenes de diferentes sensores y resoluciones (satelitales o de vehículos aéreos no tripulados) así como utilizar modeladores más sofisticados, como aquellos que arrojan como resultado la distribución del nicho ecológico adecuado para sus especies.

\section{AGRADECIMIENTOS}

El presente trabajo se realizó con el financiamiento del Proyecto Interno UAT2014-68, de la Universidad Autónoma de Tamaulipas. Los autores desean agradecer a quienes brindaron apoyo en campo, especialmente a Mariel Aimé López Rivas, Evelyn Ríos, Gerardo Vázquez 
Guevara y Armando Casas González. También a Juan Verdines y su esposa Doña Sarita, originarios del ejido Valle Hermoso, a "Don Ernesto", del ejido Marcela y a "Don Noé", del Ejido El Aserradero, por compartir sus conocimientos empíricos de los bosques de oyamel en el municipio de Miquihuana; así mismo, se agradecen los datos de nevadas en el Cerro del Diente, proporcionados por los habitantes de San Carlos, los señores José Guevara Carranco y Noé Vega Pérez "Veguita".

\section{LITERATURA CITADA}

Arranz, A.; López,C.; Salinas, C.; Zuñiga, M.; Montorio,R.; Pueyo, A. (2013). El potencial de Google Earth aplicado al análisis espacial en geografía. In M. J. González, M.; De Lázaro, M.L.; Marrón (Ed.), Innovación en la enseñanza de la geografía ante los desafios sociales y territoriales (p. 464). Zaragoza, España: Institución Fernando el Católico, Organismo autónomo de la Excma. Diputación de Zaragoza.

Ávila, C.; Aguirre, J.; García, E. (1994). Variación estructural del bosque de oyamel (Abies hickelii Flous y Gaussen) en relación con factores ambientales en el pico de Orizaba, México. Investigación Agraria, Sistemas y Recursos Forestales, 3(1), 5-17. https://doi.org/https://doi.org/10.5424/516

Briones Villarreal, O. L. (1991). Sobre la flora, vegetación y fitogeografía de la Sierra de San Carlos, Tamaulipas. Acta Botanica Mexicana, (16), 15. https://doi.org/10.21829/abm16.1991.624

Castellanos-Acuña, D., Lindig-Cisneros, R. A., Silva-Farias, M. A., \& Sáenz-Romero, C. (2014). Zonificación altitudinal provisional de Abies religiosa en un área cercana a la Reserva de la Biósfera de la Mariposa Monarca, Michoacán. Revista Chapingo, Serie Ciencias Forestales y Del Ambiente, 20(2), 215-225. https://doi.org/10.5154/r.rchscfa.2013.11.041

Cavazos, C. (2000). Evaluación del bosque mesófilo de montaña en San Carlos, Tamaulipas. Universidad Autónoma de Nuevo León.

Chuvieco, E. (2011). Teledetección Ambiental. La observación de la tierra desde el espacio. (Tercera). Barcelona, España: Editorial Ariel.

Domínguez, A. F. A. (1991). Nueva Localidad para Abies vejari Martínez. Revista Ciencia Forestal En México, 16(70), 3-22.

Earle, C. J. (2007). Conifers of México. Abies religiosa (Kunth) Schlechtendahl et Chamisso 1830. Retrieved February $15, \quad$ 2019, from https://www.conifers.org/pi/Abies_religiosa.php

Encina, J.A.; Encina, F.J.; Mata, E.\& Váldez, J. (2008). Aspectos estructurales, composición florística y caracterización ecológica del bosque de oyamel de la siera de Zapalinamé, Coahuila, México. Boletín de La Sociedad Botánica Mexicana, 83, 13-24.

ESRI. (2006). ArcGIS 9. Using ArcGIS DesKtop. (p. 435). p. 435. ESRI.

Farjon, A. (2013). Abies vejarii. The IUCN Red List of Threatened Species 2013: e.T42302A2970671. Retrieved from International Union for Conservation of Nature website: https://www.iucnredlist.org/species/42302/2970671

Gámez, R. (2011). Guía para la elaboración de mapas de distribución potencial. Retrieved from Universidad Veracruzana website: https://www.uv.mx/personal/mgamez/files/2010/07/guia-version-germoplasma.pdf

García, J. (2013). Diversidad de Macromicetos en el estado de Tamaulipas, México. (Universidad Autónoma de Nuevo León). Retrieved from http://eprints.uanl.mx/3445/1/1080256810.pdf

Gardner, M. (2013). Abies guatemalensis var. guatemalensis. The IUCN Red List of Threatened Species 2013: e.T46186032A2795168. Retrieved from International Union for Conservation of Nature website: https://www.iucnredlist.org/species/46186032/2795168

Gernandt, D. S., \& Pérez-De La Rosa, J. A. (2014). Biodiversidad de Pinophyta (coníferas) en México. Revista Mexicana de Biodiversidad, 85(SUPPL.). 
https://doi.org/10.7550/rmb.32195

Gobierno del Estado de Tamaulipas. (2011). Atlas de Riesgo de los Municipios de Mainero, San Carlos, San Nicolás y Villagrán del Estado de Tamaulipas. Retrieved from https://www.tamaulipas.gob.mx/proteccioncivil/wpcontent/uploads/sites/36/2011/12/ATLAS-DE-RIESGOS-DE-MAINERO-SANCARLOS-SAN-NICOLAS-Y-VILLAGRAN.pdf (

Gómez, R. (2003). Estado del conocimiento de Abies religiosa (H.B.K.) Schl et Cham. Universidad Autonoma Chapingo.

Guerrero-Hernández, R., Muñiz-Castro, M. Á., Vázquez-García, J. A., \& Ruiz-Corral, J. A. (2019). Estructura del bosque mesófilo de montaña y su reemplazo por bosque de Abies en dos gradientes altitudinales del occidente de México. Botanical Sciences, 97(3), 301. https://doi.org/10.17129/botsci.2206

Gutiérrez, O. , Cámara, R., \& García, L. V. (2016). Nicho ecológico y distribución geográfica del Pinsapó (Abies pinsapo Boiss). Takurunna, 59-87. Retrieved from http://www.sierrabermeja.es/pdf/Takurunna-6-7-nicho-ecologico-y-distribuciongeografica-del-pinsapo.pdf

Gutiérrez Hernández, O., Cámara-Artigas, R., \& García, L. V. (2018). Predictive modeling in Biogeography: Applying ecological niche modelling in Physical Geography. Boletin de La Asociacion de Geografos Espanoles, 2018(78), 88-126. https://doi.org/10.21138/bage.2395

Harlow,M.; Jones, C.; Tucker, C. (2006). ArcGIS® 9. Geoprocessing Commands Quick Reference Guide. Retrieved from ESRI website: http://webhelp.esri.com/arcgisdesktop/9.3/pdf/geoprocessing_quick_guide.pdf

Hernández, M. A. (1985). Distribución y utilidad de los Abies en México. Investigaciones Geográficas, 15, 75-118. Retrieved from http://www.scielo.org.mx/scielo.php?pid=S0188-46111985000100003\&script=sci_arttext

Hijmans, R. J., Cameron, S. E., Parra, J. L., Jones, P. G., \& Jarvis, A. (2005). Very high resolution interpolated climate surfaces for global land areas. International Journal of Climatology, 25(15), 1965-1978. https://doi.org/10.1002/joc.1276

IBM. (2015). IBM SPSS Statistics for Windows. Armonk, NY: IBM Corp.

INEGI, I. N. de E. y G. (2013). Carta de Vegetación y Uso del Suelo, Serie V. Datos vectoriales. Retrieved from http://www.beta.inegi.org.mx/temas/mapas/usosuelo/

IUCN. (2016). The IUCN Red List of Threatened Species. Versión 2016-1. Retrieved from International Union for Conservation of Nature website: www.iucnredlist.org.

Lambin, E. F. (1994). Modelling deforestation processes: a review. Tropical Ecosystem Environment Observations by Satelites TREES Series B. Luxemburg.

López, M. A. (2015). Análisis de Impacto Ambiental por Aprovechamiento Forestal Maderable en el Municipio de Miquihuana, Tamaulipas. Universidad Autónoma de Tamaulipas.

Luvezute, R.M.; Viali, L.; Alexandre, R. (2014). Utilização dos recursos do Google Earth $^{\mathrm{TM}} \mathrm{e}$ do Google Maps ${ }^{\mathrm{TM}}$ no ensino de ciências. Revista Latinoamericana de Tecnología Educativa, 13(2), 89-101.

Manzanilla, H. (1974). Investigaciones epidométricas y silvícolas en bosques mexicanos de Abies religiosa. México: Dirección General de Información y Relaciones Públicas, Secretaría de Agricultura y Ganadería.

Martínez-Méndez, N., Aguirre-Planter, E., Eguiarte, L. E., \& Jaramillo-Correa, J. P. (2016). Modelado de nicho ecológico de las especies del género Abies (Pinaceae) en México: Algunas implicaciones taxonómicas y para la conservación. Botanical Sciences, 94(1), 362-371. https://doi.org/10.17129/botsci.508

Nieto, P. C. (1995). Estudio sinecologico del bosque de Oyamel de la cañada de Contreras, distrito federal. Retrieved from http://www.sidalc.net/cgi-bin/wxis.exe/?IsisScript= CENIDA.xis\&method $=$ post $\&$ formato $=2 \&$ cantidad $=1 \&$ expresion $=m f n=055808$

Peralta-Carreta, C., Solórzano, J. V., Fernández-Montes De Oca, A., \& Gallardo-Cruz, J. A. (2016). Sistemas aéreos pilotados de forma remota y clasificación orientada a objetos: Un acercamiento al análisis submétrico de una zona periurbana. Ecosistemas, 25(1), 90-93. https://doi.org/10.7818/ECOS.2016.25-1.13 
Recibido:

18/marzo/2019

Aceptado:

15/noviembre/2019
Pineda, M.; Ortega, M.; Sánchez, R.; Ortiz, G.\& Vázquez, G. (2013). Estructura poblacional de Abies religiosa (Kunth) Schltdl. et Cham., En el ejido el conejo del parque nacional cofre de Perote, Veracruz, México. Revista Chapingo, Serie Ciencias Forestales y Del Ambiente, 19(3), 375-385. https://doi.org/10.5154/r.rchscfa.2012.11.058

Requena, G. N. (2013). Uso de un sistema de información geoespacial para la evaluación socioeconómica de los servicios ambientales en la Cuenca Guayalejo-Tamesí (Tamaulipas, México). (Universidad de Sevilla). Retrieved from https://www.educacion.gob.es/teseo/imprimirFichaConsulta.do;jsessionid=96D4D1D5 8569B3671791F3AD93957D70?idFicha=352625

Rzedowski, J. (2006). Vegetación de México. (Primera). Comisión Nacional para el Conocimiento y Uso de la Biodiversidad.

SEMARNAT. (2007). Anuario Estadístico de la Producción Forestal.

SEMARNAT. (2010). Norma Oficial Mexicana NOM-059-SEMARNAT-2010, Protección ambiental-Especies nativas de México de flora y fauna silvestre-Categorías de riesgo y especificaciones para su inclusión, exclusión o cambio-Lista de especies en riesgo.

Valdez, V.; Foroughbakhch, R; Alanís, G. (2003). Distribución relictual del bosque mesófilo de montaña en el Noreste de México. Ciencia UANL, 6(3), 360-365.

Villers, L.; García del Valle, L.; López, J. (1998). Evaluación de los bosques templados en México: una aplicación en el Parque Nacional Nevado de Toluca. Investigaciones Geográficas, 37, 7-19.

Williams, C. G. (2009). Conifer Reproductive Biology (Springer, Ed.). https://doi.org/10.1007/ 978-1-4020-9602-0

Zavala, M.A.;Díaz-Sierra, R.; Purves, D.; Zea, G.E.; Urbieta, I. R. (2006). Modelos espacialmente explícitos. Ecosistemas, 15(3), 88-99. Retrieved from https://www.revistaecosistemas.net/index.php/ecosistemas/article/view/165 